\title{
Transcriptome comparison reveals key candidate genes in response to vernalization of Oriental lily
}

\author{
Wenqi Li, Xiaohua Liu and Yingmin Lu*
}

\begin{abstract}
Background: Oriental hybrid lily 'Sorbonne', a very important cut flower for lily, is enjoyed great popularity in the world, but it must experience a period of low winter temperature to initiate or accelerate the flowering process. To gain a better understanding of the temperature signaling pathway and the molecular metabolic reactions involved in the vernalization response, a genome-wide transcriptional analysis using RNA-Seq was performed.
\end{abstract}

Results: $188,447,956$ sequencing reads was assembled into 66,327 unigenes and showed similarity to known proteins in the Swiss-Prot protein database, and 2,893, 30,406 and 60,737 unigenes aligned to existing sequences in the KEGG, COG, and GO databases. Based on qRT-PCR results, we studied the expression of three signal regulation pathways genes-the plant hormones signal transduction (LOAP2, LOIAA1, LOARF10), the DNA methylation (LOCMT, LOFLD), and vernalizatin pathway (LOFLC, LOVRN1, LOVRN2, LOFT, LOSOC1, LOLFY, LOSVP) in the immature flower buds of Oriental hybrid lily. In addition, we identified two vernalizaiton-related genes (LOSVP and LoVRN1) from the CDNA library, which appear to be promising candidates for playing key roles in the development and response of flowering in Oriental lily plants, and LOSVP had a function in delaying flowering but LoVRN1could promote flowering early.

Conclusions: We collected a sample for transcriptome sequencing and comparison when the bulb's apical meristem was in the time of floral transition when the apical meristem had not converted into the morphological differentiation process, which helped to obtain more genes playing key roles in the floral induction pathways. The upstream and downstream relationship between different genes were forecasted by the analysis of genes' expression levels in a wide range of time. Future research that is targeted towards how genes interact on each other, which will promote establishing and perfecting the molecular mechanisms of floral induction pathway by vernalization.

Keywords: Vernalization, Lily, Transcriptome, RNA-Seq, Flower differentiation

Abbreviations: BLAST, Basic Local Alignment Search Tool; COG, Clusters of Orthologous Groups; DGE, Digital Gene Expression; EST, Expressed Sequence Tag; FDR, False Discovery Rate; GO, Gene Ontology; KEGG, Kyoto Encyclopedia of Genes and Genomes Pathway; NCBI, National Center for Biotechnology Information; qRT-PCR, Real-time Quantitative Reverse Transcription Polymerase Chain Reaction; RACE, Rapid Amplification of cDNA Ends; RPKM, Number of Reads per Kilobase per Million Clean Reads; SAM, Shoot Apical Meristem

\footnotetext{
* Correspondence: luyingmin@bjfu.edu.cn

College of Landscape Architecture \& China National Engineering Research

Center for Floriculture, Beijing Forestry University, No.35 Qinghua East Road,

Haidian District, Beijing 100083, China
}

(c) 2016 The Author(s). Open Access This article is distributed under the terms of the Creative Commons Attribution 4.0 International License (http://creativecommons.org/licenses/by/4.0/), which permits unrestricted use, distribution, and reproduction in any medium, provided you give appropriate credit to the original author(s) and the source, provide a link to the Creative Commons license, and indicate if changes were made. The Creative Commons Public Domain Dedication waiver (http://creativecommons.org/publicdomain/zero/1.0/) applies to the data made available in this article, unless otherwise stated. 


\section{Background}

Vernalization is a complicated process of plant development that is essential for plants to grow in unfavorable environmental conditions, which occurs during cold environment, and flowering only occurs some weeks or even some months later when some other conditions, including the presence of certain photoperiods and ambient temperatures, are met [1]. It is a temporary suspension of vernalization for plants of obvious growth containing meristems. The transitions of vernalization are regulated by chilling temperatures and/or short photoperiods. We have learnt some knowledge about the molecular mechanisms indicating vernalization from the model plant Arabidopsis thaliana and cereals.

In Arabidopsis thaliana, the progressive repression and stable silencing of FLOWERING LOCUS C (FLC), is central to the vernalization mechanism. $F L C$ encoded a MADS domain protein acting as a repressor of flowering $[2,3]$. There were also some other genes been found to related to vernalization-responsiveness in Arabidopsis [4]. FLOWERING LOCUS T (FT) and SUPPRESSOR OF OVER-EXPRESSION OF CONSTANS 1 (SOC1), two floral promoters, were repressed transcription by $F L C$ [5]. That is, $F L C$ is highly expressed in plants that have not experienced vernalization $[6,7]$, and then $F L C$ protein was binded to the promoter of $S O C 1$ and sequences in an FT intron to repress transcription of both these genes [6, 7], which delays flowering. In addition, some other target genes or FLC orthologues were key to the developmental release that enables flowering $[8,9]$ in other plant species.

In cereals, there were two main regulatory pathways leading to the transition to reproductive development at the molecular levels-the vernalization pathway and the photoperiod pathway [10-12]. One of the major genes controlling vernalization-induced flowering is VERNALIZATION 1 (VRN1). VRN1 is similar to Arabidopsis thaliana APETALA1 (AP1), CAULIFLOWER (CAL) and FRUITFULL (FUL), which are MADS-box transcription factors and identity genes in meristem [13]. VRN1 was a major determinant of winter/spring growth habit in cereals. Neither the mechanism behind repression of VRN1 prior to vernalization in vernalization-requiring plants nor the mechanism by which VRN1 leads to transition to reproductive development was fully understood. Another major gene controlling vernalization-induced flowering in cereals is VERNALIZATION 2 (VRN2), which is a floral repressor that delays flowering until plants are vernalized [14].

Besides, there was another group of MADS-box genes that have a putative function in the transition to flowering belong to the SHORT VEGETATIVE PHASE (SVP)like MADS-box genes. SVP-like genes in A. thaliana, Hordeum vulgare, and T. aestivum act as negative regulators of flowering $[15,16]$. In $T$. aestivum, TaVRT2, a
SVP-like gene is down-regulated by vernalization and can bind the CArG-box in the VRN1 promoter and interacts with VRN1 and VRN2 proteins [17].

Lilies, monocotyledonous ornamental plants, are one of the most important flowering crops [18], which flowering relies on a combination of integrating effects of endogenous and external signals [19]. Vernalization in Oriental Lilies, which are perennial plants, generally requires a minimum of eight weeks at low temperatures $\left(4{ }^{\circ} \mathrm{C}\right)$. It was indicated that low temperatures could control vernalization in lily. But there was few studies carried out to date on the transcription factors and vernalization pathway in lily. Here we report the use of the RNA-seq approach to identify venalization-related genes during flower development of Oriental lily.

Recently, based on Illumina sequencing technology, RNA-sequencing (RNA-Seq) technology has become the most powerful and popular tool for plants that lack reference genome information, which is less costly, more efficient, and more accurate and sensitive profiles than other techniques [20]. RNA-Seq has been successfully applied to many species, including Takifugu rubripes [21], Streptococcus mutans [22], Streptococcus mutans [23], Soybean [24] and tree peonies [25]. Here, we used RNA-Seq technology to characterize and identify the expression of a large number of genes, especially those expressed differentially during vernalization phase. Our study allows us to investigate the genome-wide interaction dynamics of transcription factors and to identify pathways regulated by vernalization in lily flower development.

\section{Methods}

Total RNA isolation and plant material

Commercial bulbs of Oriental hybrid lily "Sorbonne" purchased from a local nursery in Yunnan Province after harvest were used. Bulbs were selected with an even size of ca. $20 \mathrm{~g}$. and we stored them in moist sawdust at $4{ }^{\circ} \mathrm{C}$ until being planted. The expression of SOC1 gene increases sharply by qRT-PCR after Oriental Hybrid Lily'Sorbonne' being stored for 42 days which usually indicates the floral transition (Fig. 1). The previous period before the floral transition is the floral induction phase. After the floral transition, the bulb's apical meristem converts into floral bud morphological differentiation period. At the beginning of the low temperature storage, the unvernalized sample, namely the dormant sample, was collected from the shoot apical meristem (SAM). The vernalized sample, namely the dormancybreaking sample, was collected from SAM (finished vernalization) after being stored for 42 days, then the flower bud differentiation sample was collected from SAM of squaring stage after being planted. All samples were preserved at $-80{ }^{\circ} \mathrm{C}$ for RNA isolation. Total RNA was extracted from the tissues with an Easyspin Isolation 


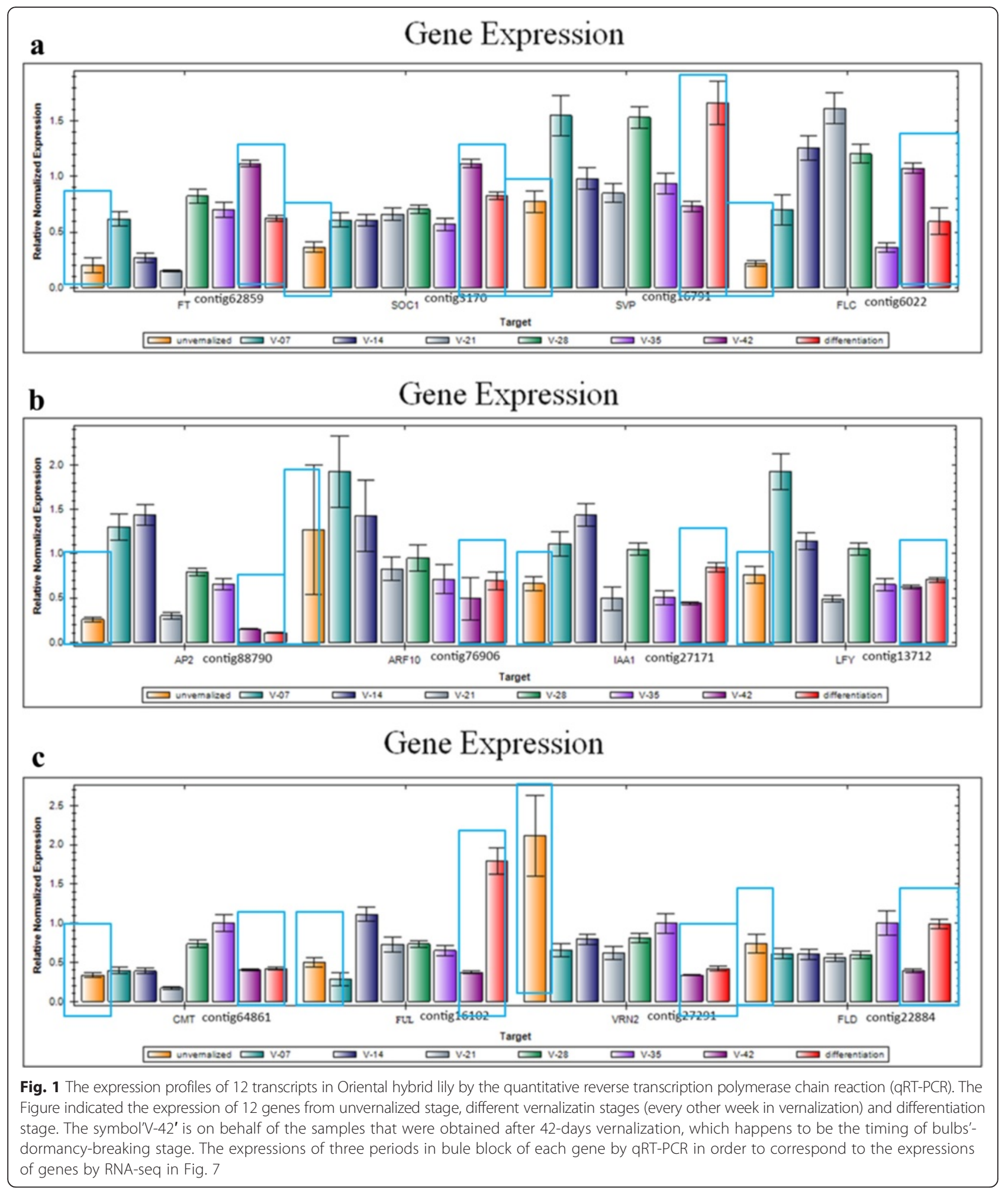

System of RNAisomate RNA (Aidlab Biotech, Beijing, China). RNA quality was verified by a 2100 Bioanalyzer (Agilent Technologies, Santa Clara, CA, USA). In addition, we used a pooled RNA mixture containing $60 \mu \mathrm{g}$ RNA from samples to prepare cDNA.
Library construction and transcriptome sequencing

Each total RNA extract was first treated with RNase-free DNase I (TaKaRa, China) to remove contaminating DNA, and then concentrated the mRNA content by capturing on magnetic oligo (dT) beads. Then second- 
strand cDNA was synthesized using RNase H, dNTPs, DNA polymerase I, and appropriate buffers with a SuperScript Double-Stranded cDNA Synthesis kit (Invitrogen, Camarillo, CA). Then, cDNA was depurated and settled end repair with an elution buffer and by addition of poly (A). Sequencing adaptors were then ligated to the fragments, and agarose gel electrophoresis used to select the range of fragments suitable for PCR amplification. Sequencing using an Illumina HiSeq 2000 platform was performed at the ShoBiotechnology Corporation (SBC), Shanghai, China following the manufacturer's protocols. Each sample was sequenced with three cDNA reactions independently as biological replicates.

\section{Analysis of transcriptome sequencing results}

Using scaffolding contig methods with a minimum contig length of $\geq 400$, pre-processing and de novo assembly were carried out including the removal of the adapter sequences, ambiguous inner regions, shorter-than-15-nucleotide sequences, and low quality $(\mathrm{Q} 20,20)$ sequences using the SOAP2 aligner [26] configured to allow up two mismatches, discard sequences with "N" $\mathrm{s}$ and return all optimal alignments. After assessing the different $K$-mer sizes, the primary unigenes of three samples were assembled, generating the final unigenes which were used for BLASTx searches against Swiss-Prot protein database (2014.05) and the UniProt database (2014.06). Blast2GO program [27] was used to assign GO terms. Finally, 66,327 unigene sequences were aligned into 25 COGs to classify and predict functions. In addition, using BLASTx (E-value threshold $10^{-5}$ ), we carried out KEGG annotations based on the KEGG database.

\section{Identification and bioinformatics annotation of different gene}

RPKM method was used to calculate the expression. Using DEGseq, the difference in gene expression between samples were detected [28]. Then according to the Audic \& Claverie method [29], a rigorous algorithm was developed to identify genes expressed differentially. FDR was used to decide the threshold of P-value in tests and analysis. When $\log 2$ ratio greater than 1 and FDR is less than 0.05 and between the accessions, the genes were regarded as expressed differentially.

\section{PCR validation by quantitative real-time PCR (qPCR)}

Ten candidate genes were selected to determine using quantitative real time PCR (qPCR). The samples were collected from the dormant, different dormancybreaking stages and different flower bud differentiation stages, as described above. According to the manufacturer's instructions, with Superscript II reverse transcriptase (Invitrogen, Carlsbad, CA, USA), first-strand cDNA synthesis was performed. qRT-PCR were based on SYBR_Green I (TOYOBO', Japan) in a DNA Engine Opticon 2 machine (MJ Research, Waltham, MA) and TaKaRa ExTaq RT PCR Kit. A set of gene-specific primer pairs (sequences given in Table 1) was designed by Beacon Designer. The internal reference gene LoTIP1 (F: CGAAGCCAGAAACGGAGAAGAAT, R: GGGTAGG GTGGATTGGGAAGA) was used as a reference. Each $25 \mu \mathrm{l}$ qPCR reaction contained $10 \mathrm{ng} \mathrm{cDNA}, 0.2 \mu \mathrm{M}$ of each primer and $10 \mu \mathrm{lSYBR}$ Green PCR master mix, and the amplification regime consisted of an initial denaturation of $95{ }^{\circ} \mathrm{C} / 60 \mathrm{~s}$, followed by 40 cycles of $95^{\circ} \mathrm{C} / 15 \mathrm{~s}$, $55^{\circ} \mathrm{C} / 15 \mathrm{~s}, 72{ }^{\circ} \mathrm{C} / 20 \mathrm{~s}$. All experiments were operated in biological triplicates using the $2^{-\triangle \Delta \mathrm{Ct}}$ method [30], the results were calculated.

\section{Isolation of LOSVP and LoVRN1 genes}

The complete sequence of the LoSVP and LoVRN1 were isolated using rapid amplification of cDNA ends (RACE). The CDS sequences in the Oriental hybrid lily EST database were Blast-searched with the homologous fragments of SVP in Arabidopsis thaliana (AK226537.1) and the homologous fragments of VRN1 in Festuca arundinacea (FJ793194.1) from NCBI. Two genes found in the Oriental hybrid lily EST database have the highest identity with gene (AK226537.1) and gene (FJ793194.1) were named as LoSVP and LoVRN1, respectively. One microgram of mRNA isolated from SAM was converted into $3^{\prime}$ - and $5^{\prime}$-RACE-ready cDNAs with the $3^{\prime}$ and $5^{\prime}$ CDS primers by the SMART RACE cDNA amplification kit (Clontech, Palo Alto, CA, USA).. Specific primers LoSVP $5 f$ (5'-CCATGGGACTGAACGATCAGCTT GCG-3'), LoSVP 3r (5'-GAATTCCAGTTGCATGT TCTCCTCTG-3') and LoVRN1 5f (5'- CTCTGGAT CCCCTCTCATCATCACA-3'), LoVVRN1 3r (5'-GAA ACACTGGGATCCACTGCCCATG-3') were designed for amplification of the $5^{\prime}$ and $3^{\prime}$ ends according to the partial sequence of the LoSVP and LoVRN1 of the EST clone, respectively. Reactions were subjected to the following conditions: $94^{\circ} \mathrm{Cfor} 3 \mathrm{~min}$ followed by 35 cycles of amplification $\left(94{ }^{\circ} \mathrm{C}\right.$ for $30 \mathrm{~s}, 52{ }^{\circ} \mathrm{C}$ for $30 \mathrm{~s}, 72{ }^{\circ} \mathrm{C}$ for $1 \mathrm{~min}$ ) and a 10 -min final extension at $72{ }^{\circ} \mathrm{C}$. Then the PCR products were cloned into pGEMT-T Easy vector. Plasmid DNAs were purified from overnight cultures of three independent clones to sequence for each transformation, and we aligned all resulting sequences with the partial cDNA sequence using the GCG program. Finally, the full-length LoSVP and LoVRN1 cDNA was isolated.

\section{Analysis of the phylogenetic relationship}

Nucleotide sequences were aligned with the program ClustalW [31]. Based on Poisson correction model, neighbor-joining analyses of amino acid sequences included in MEGA4 were used [32] by calculating genetic 
Table 1 Primers used in real-time quantitative PCR (RT-qPCR)

\begin{tabular}{|c|c|c|c|c|c|}
\hline Unigene id & $\begin{array}{l}\text { Protein } \\
\text { description }\end{array}$ & $\begin{array}{l}\text { Forward primer } \\
\text { sequence }\left(5^{\prime}-3^{\prime}\right)\end{array}$ & $\begin{array}{l}\text { Reverse primer } \\
\text { sequence }\left(5^{\prime}-3^{\prime}\right)\end{array}$ & Length (bp) & $\begin{array}{l}\text { Correlation between } \\
\text { RNA-Seq and qRT-PCR }\left(r^{2}\right)\end{array}$ \\
\hline Contig6022 & $\begin{array}{l}\text { FLOWERING } \\
\text { LOCUS C }\end{array}$ & CCTGGTGGAGAAGACGATGAGTG & AACAAGATCAGCCGCCAAGTCA & 117 & 0.98 \\
\hline Contig27291 & Vernalization 2 & GCTGCCAAACCCTGGTCATCA & CATTATGCCTGGTGGTGAGTTCCC & 111 & 0.99 \\
\hline Contig62859 & FT-like protein & GCGGCAACGATCTCAGAA & CTCAAATATGGGTTACTGGGACTC & 89 & 0.95 \\
\hline Contig88790 & $\begin{array}{l}\text { AP2-type } \\
\text { transcription } \\
\text { factor }\end{array}$ & GGTITACTTGGGTGGTTTC & TCCTCCTTCGTCAGATTG & 153 & 0.97 \\
\hline Contig3170 & $\begin{array}{l}\text { Suppressor of } \\
\text { overexpression of } \\
\text { CO1 }\end{array}$ & GCCTCGTGAAGAAGA & CTCCAACAGAATCCTC & 122 & 0.94 \\
\hline Contig88645 & $\begin{array}{l}\text { CBF-like } \\
\text { transcription } \\
\text { factor }\end{array}$ & CAACTCGCTGGATGGCTGCT & GCCACTCCGCCACACTCAAT & 115 & 0.98 \\
\hline Contig13712 & LFY & CGAAGAAGAACGGGCTGGACTACT & AGGCAGTGGAAGGCGTAGCA & 134 & 0.94 \\
\hline Contig22259 & Maf-like protein & CAAGATTCAAACCCGAGATG & CGAGACGATGATGAGGAT & 99 & 0.94 \\
\hline Contig76906 & $\begin{array}{l}\text { Auxin response } \\
\text { factor } 10\end{array}$ & TAGATGGCACGGGCGAATATACCT & CACACGCAGCCTCTTCACAGT & 113 & 0.97 \\
\hline Contig27171 & IAA type protein & GTTCTCTTGCTTCACCATC & ACATACTCCGTTCCATTCA & 104 & 0.98 \\
\hline
\end{tabular}

distance. By bootstrapping, we tested the confidence of reconstructed clades [33]. As a rule, nodes with bootstrap values greater than 70 are significantly supported with $95 \%$ probability [34]. The Genbank accession numbers for amino acid sequences of the SVP gene in other plants used are Theobroma cacao (XP 007047796), Populus trichocarpa (XP 002310310), Paulownia kawakamii (AAF22455.1), Vitis vinifera (XP 002269295), Vitis vinifera (AFC96914.1), Malus domestica (ABD66219.1), Brassica rapa (ABI96182.1), Brassica napus (AFM77910.1), Capsella rubella (XP 006294891), Arabidopsis thaliana (AFU85632.1), Arabidopsis thaliana (BAE98676.1), Petunia $\times$ hybrida (ACV74250.1), Actinidia chinensis (AFA37963.1), Actinidia chinensis (AFA37967.1), Elaeis guineensis (AAW66885.1). The Genbank accession numbers for amino acid sequences of the VRN1 gene in other plants used are Festuca arundinacea (ACN81330.1), Lolium perenne (AEV22381.1), Triticum aestivum (ABF57926.1), Dendrocalamus latiflorus (AAR32119.1), Oryza saliva (Baa94342.1), Zea mays (AFW67591.1), Elaeis guineensis (AAQ03221.1), Alpinia oblongifolia (ABS83558.1), Cymbidium ensifolium (AFQ31623.1), Vitis vinifera (AAT07447.1), Tulipa gesneriana (BAJ09453.1), Lilium longiflorum (ADT78582.1).

Arabidopsis transformation and transgenic plants analysis LoVRN1 and LoSVP were excised from the PGEM-T easy vector using $\mathrm{XbaI}$ and SmaI restriction enzymes and inserted in to the binary vector PBI121 (Clontech) under the control of cauliflower mosai cvirus (CaMV) $35 \mathrm{~S}$ promoter. After confirmation of the sequence, Agrobacterium tumefaciens strain GV1301 competent cells were prepared and transformed by electroporation according to Mattanovich et al. [35]. Arabidopsis thaliana ecotype Columbia ( $\mathrm{Col}$ ) plants were transformed using the floral-dip method [36]. The expression of the transgene was confirmed by DNA gel blot analysis, RT-PCR, and immuno-blotting using anti-PBI121 antibody (Clontech, Japan). Wild type Arabidopsis seedlings and 35S: LoVRN1-sPBI121 T1 Arabidopsis transgenic seedlings and 35S: LoSVP-sPBI121 T1 Arabidopsis transgenic seedlings were grown for three days under $0.5 \times$ MS with $1 \%$ sucrose media and then were transplanted into the soil, respectively. Observe and compare the flowering time and characteristics of the flower bud differentiation between the transgenic Arabidopsis T1 plants and wild-type Arabidopsis plants. The blade length and plant fresh weight of the transgenic Arabidopsis T1 plants and wild-type Arabidopsis plants were measured in seedling stage, early blooming stage and seed maturing stage, respectively.

\section{Results}

\section{Illumina sequencing data and de novo assembly}

To enrich the number of genes involved in our transcriptome, cDNA samples were extracted from total RNA isolated from SAM for three libraries (dormant, dormancy-breaking and flower bud differentiation samples). Approximately 50 million for the dormant sample and 137 million for the latter two samples (the dormancy-breaking and flower differentiation samples) were obtained. After data cleaning and stringent quality checks, $115,421,520$ raw reads containing a total of 17.7 Gb nucleotides were obtained. The average read size, 
GC percentage and Q20 percentage were $90 \mathrm{bp}, 43.00 \%$ and $93.80 \%$, respectively. 122,464 contigs were assembled with an average length of $624 \mathrm{bp}$ based on the high quality reads. With an average length of $1,015 \mathrm{bp}$, we further assembled the contigs into 68,036 scaffolds including 31,486 scaffolds larger than $1000 \mathrm{bp}$. All de novo assembly yielded 66,327 unigenes with an average length of 1,037 bp (Tables 2 and 3). 30,254 (45.6\% of the total) had significant similarity to known proteins in the Swiss-Prot database. The lack of L. oriential genome and EST information meant that 36,073 (54.4\% of the total) unigenes had no Swiss-Prot annotation (Table 3). To demonstrate the quality of sequencing data, ten unigenes were randomly selected and ten pairs of primers were designed for qRT-PCR, and then the products were confirmed by biological Sanger sequencing.

\section{Functional classification and gene annotation}

To further evaluate the effectiveness of our annotation process and the completeness of our transcriptome library, the annotated sequences were randomly searched for genes with COG classifications. Of 30,254 hits, 30,406 sequences had a COG classification. Among the 25 COG categories, the cluster for 'signal transduction mechanisms' (5351, $17.60 \%$ ) represented the largest group, followed by 'posttranslational modification, protein turnover, chaperones' $(4185,13.76 \%)$ and 'general function prediction only' (3916, $12.88 \%$ ). The following categories, 'nuclear structure' (137, $0.45 \%)$, 'extracellular structures' (92, $0.30 \%$ ) and 'cell motility' (6, $0.02 \%)$,, represented the smallest groups (Fig. 2).

The GO assignments were also used to classify the functions of the predicted lily genes. Based on sequence homology, 15,425 sequences can be categorized into 53 groups (Fig. 3). In each of the three main GO classifications, the 'metabolic process', 'cell part' and 'binding' terms were dominant, respectively. We also found a high percentage from the 'cellular process', 'membrane-enclosed lumen' and 'catalytic activity' categories, but few from 'metallochaperone activity', 'cell junction' and 'locomotion' (Fig. 3). The $\mathrm{GO}$ analysis indicated that the identified genes were associated with various biological processes.

Based on a comparison against the KEGG database using BLASTx with an Evalue cutoff of $<10^{-5}$, of the 66,327 unigenes, 16,601 (25.03\%) had significant matches in the database and were assigned to 268 KEGG pathways
(Table 4). The most representative pathways were 'pyrimidine metabolism' (278 members), 'ribosome' (289 members), 'microbial metabolism in diverse environments' (413 members), 'biosynthesis of secondary metabolites' (965 members), and 'metabolism pathways' (2067 members) (Table 4). These annotations provided an efficient resource for investigating pathways, functions, and processes involved in lily vernalization. In addition, we found unigenes involved in plant hormone signal transduction pathway, indicating that ABA, IAA, ethylene and GAs hormones may play important role in hormone signal transduction pathways of lily vernalization (Fig. 4).

\section{Gene expression changes among different vernalization stages}

A RNA-Seq experiment was conducted using samples of unvernalized, vernalized and flower bud differentiation of Oriental hybrid lily and mapped the resulting reads to our reference transcriptome to determine which of the 66,327 genes were differentially expressed among the three stages, we filtered with an FDR $\leq 0.001$ and $\mid \log _{2}$ (ratio) $\mid$ $\geq 2$; During the three stages, 195 DEGs was changed significantly. On one side, some genes were downregulated from the unvernalized to vernalized stages, but up-regulated obviously at the flower bud differentiation. On the other side, it was showed that some genes increased expression at vernalized stage, but decreased transcript abundance at the flower diffferentiation stage. With an algorithm developed from the heat-map, the differentially expressed tags among the three samples were identified. Some genes were immediately expressed at the initial stage of unvernalized, while others were upregulated subsequently indicating that transcription factors induced the expression of vernalization-related genes during the regulation of temperature signaling (Fig. 5a).

In addition, the vernalized and unvernalized libraries were compared and 1907 variable genes were found a total of 808 up-regulated and 1099 down-regulated genes were detected between the two libraries. There were also 1846 up-regulated and 1954 down-regulated genes between the vernalized and flower bud differentiation libraries, 1946 up-regulated and 1027 down-regulated genes between the unvernalized and flower bud differentiation libraries (Fig. 5b). This suggests that the differentiation of expressed genes between vernalized and flower bud differentiation is larger than that between the unvernalized and

Table 2 Summary of sequencing and assembly data

\begin{tabular}{lcccccccc}
\hline Sample ID & Raw Reads (MB) & Raw Bases (GB) & Q20 Value (\%) & Raw Reads & $\begin{array}{l}\text { Quality } \\
\text { Trimed }\end{array}$ & $\begin{array}{l}\text { Adaptor } \\
\text { Trimed }\end{array}$ & $\begin{array}{l}\text { Number } \\
\text { Clean Reads }\end{array}$ & $\begin{array}{l}\text { Clean Ratio } \\
\text { unvernalized }\end{array}$ \\
vernalized & 50.8 & 5.1 & 98.5 & $50,824,066$ & $49,454,613$ & $48,900,904$ & $47,268,792$ & 93.0 \\
Flower bud & 56.5 & 5.6 & 98.5 & $56,501,972$ & $55,146,129$ & $54,528,334$ & $52,872,714$ & 93.6 \\
differentiation & 81.1 & 8.1 & 98.6 & $81,121,918$ & $79,776,697$ & $78,821,040$ & $76,896,022$ & 94.8 \\
\hline
\end{tabular}


Table 3 Summary for the Oriental hybrid lily 'Sorbonne' transcriptome

\begin{tabular}{llllllllllll}
\hline Statistics & Counts & Total Length (bp) & N25 (bp) & N50 (bp) & N75 (bp) & $\begin{array}{l}\text { Average } \\
\text { Length }\end{array}$ & $\begin{array}{l}\text { Longest } \\
\text { (bp) }\end{array}$ & $\begin{array}{l}\text { N\% } \\
\text { GC\% }\end{array}$ & $\begin{array}{l}\text { Annotation } \\
\text { Counts }\end{array}$ & $\begin{array}{l}\text { Annotation } \\
\text { Ratio\% }\end{array}$ \\
\hline Contigs & 122,464 & $76,454,985$ & 1,988 & 948 & 451 & 624 & 16,373 & 1.3 & 42.8 & \\
$\begin{array}{l}\text { Primary } \\
\text { UniGene }\end{array}$ & 68,036 & $69,046,293$ & 2,341 & 1,288 & 674 & 1,015 & 19,791 & 1.1 & 43.1 & \\
$\begin{array}{l}\text { Final } \\
\text { UniGene }\end{array}$ & 66,327 & $68,760,870$ & 2,390 & 1,333 & 693 & 1,037 & 19,791 & 1.2 & 43.0 & 30,254 & 45.6 \\
\hline
\end{tabular}

flower bud differentiation libraries, while the difference between and the unvernalized and vernalized libraries is the smallest of the three. That means, in Oriental hybrid lily, transcript abundance changed dramatically among the vernalization stages of vernalized to flower bud differentiation stage which the temperature response genes could be induced and expressed largely, and we should not ignore the expression of genes during the short-term of unvernalized to vernalized stage, because in this period, many important vernalization response genes were upand down-regulated, they would earliest determine the plant to response to the low temperatureand to play instantaneous reflection.

At the vernalized stage, genes whose transcript abundance exhibited highly dynamic changes $(\mid \log 2$ (ratio) $\mid \geq$ 4, Fig. 6) included MADS-Box genes (FLC, SOC1, $L F Y$ et al.), hormonal genes (AUX, IAA1, ASR, ARF et al.) and methylation related genes. Therefore, the change in expression patterns of distinct transcripts suggested the requirement of different development events from unvernalized to vernalized growth.

\section{qRT-PCR verifing gene expression profiles}

To verify the genes expression in our Illumina sequencing analyses, 12 DEGs were selected for qRT-PCR using samples of unvernalized, vernalized and flower bud differentiation stages originally used for RNA-Seq, all of which are known to be related to low temperature, including the genes encoding LoFLC (Flowering locus C, Contig6022), LoVRN2 (Vernalization 2, Contig27291), LoFT (FT-like protein, Contig62859), LoAP2 (AP2-type transcription factor, Contig88790), LoSOC1 (Suppressor of overexpression of CO1, Contig3170), LoLFY (LEAFY, Contig13712), LoVRN1 (Vernalization 1, Contig16102), LoSVP (Shot vegetative phase, Contig16791), LoFLD (Flowering locus D, Contig22884), LoCMT (CMT-type DNA methyltransferase, Contig64861), LoARF10 (Auxin response factor 10, Contig76906), LoIAA (IAA type protein, Contig27171). The Ct values of the LoTIP in all samples ranged from 24.0 to 26.0. All 12 transcripts showed the same expression pattern as the in silico differential analysis results from high-throughput sequencing.

These genes were selected for their key roles in regulating low temperature signal transcription, vernalization responses, and cold acclimation. The results presented in Fig. 1 showed that the expression levels of flowering integrating factors (LoFT, LoLFY, LoSOC1) were higher in vernalized and flower differentiation samples than in unvernalized sample, which indicated that the three genes may play key roles in floral transition. The expression of

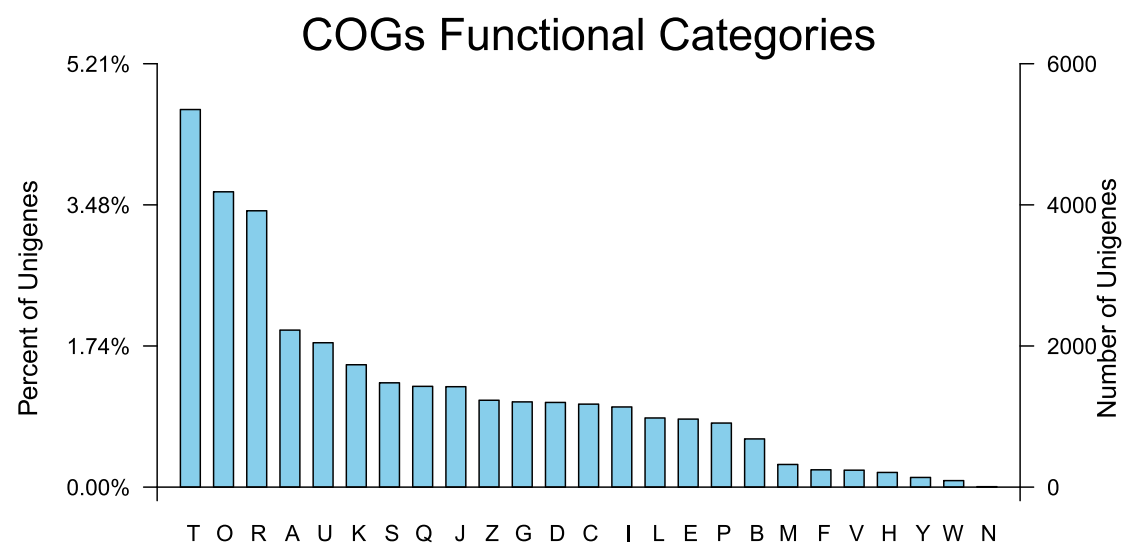

Fig. 2 COG classifications in Oriental hybrid lily 'Sorbonne'
A. RNA processing and modification

B: Chromatin structure and dynamic

C: Energy production and conversion

D: Cell cycle control, cell division, chromosome partitioning

E: Amino acid transport and metabolism

F: Nucleotide transport and metabolism

G: Carbohydrate transport and metabolism

$\mathrm{H}$ : Coenzyme transport and metabolism

I: Lipid transport and metabolism

$\mathrm{J}$ : Translation, ribosomal structure and biogenesis

K: Transcription

L: Replication, recombination and repair

M: Cell wall/membrane/envelope biogenesis

$\mathrm{N}$ : Cell motility

O: Posttranslational modification, protein turnover, chaperones

$\mathrm{P}$ : Inorganic ion transport and metabolism

Q: Secondary metabolites biosynthesis, transport and catabolism

R: General function prediction only

T: Signal transduction mechanisms

$\mathrm{U}$ : Intracellular trafficking, secretion, and vesicular transport

$V$ : Defense mechanisms

W: Extracellular structures

$Y$ : Nuclear structure

Z: Cytoskeleton

$\mathrm{S}$ : Function unknown 


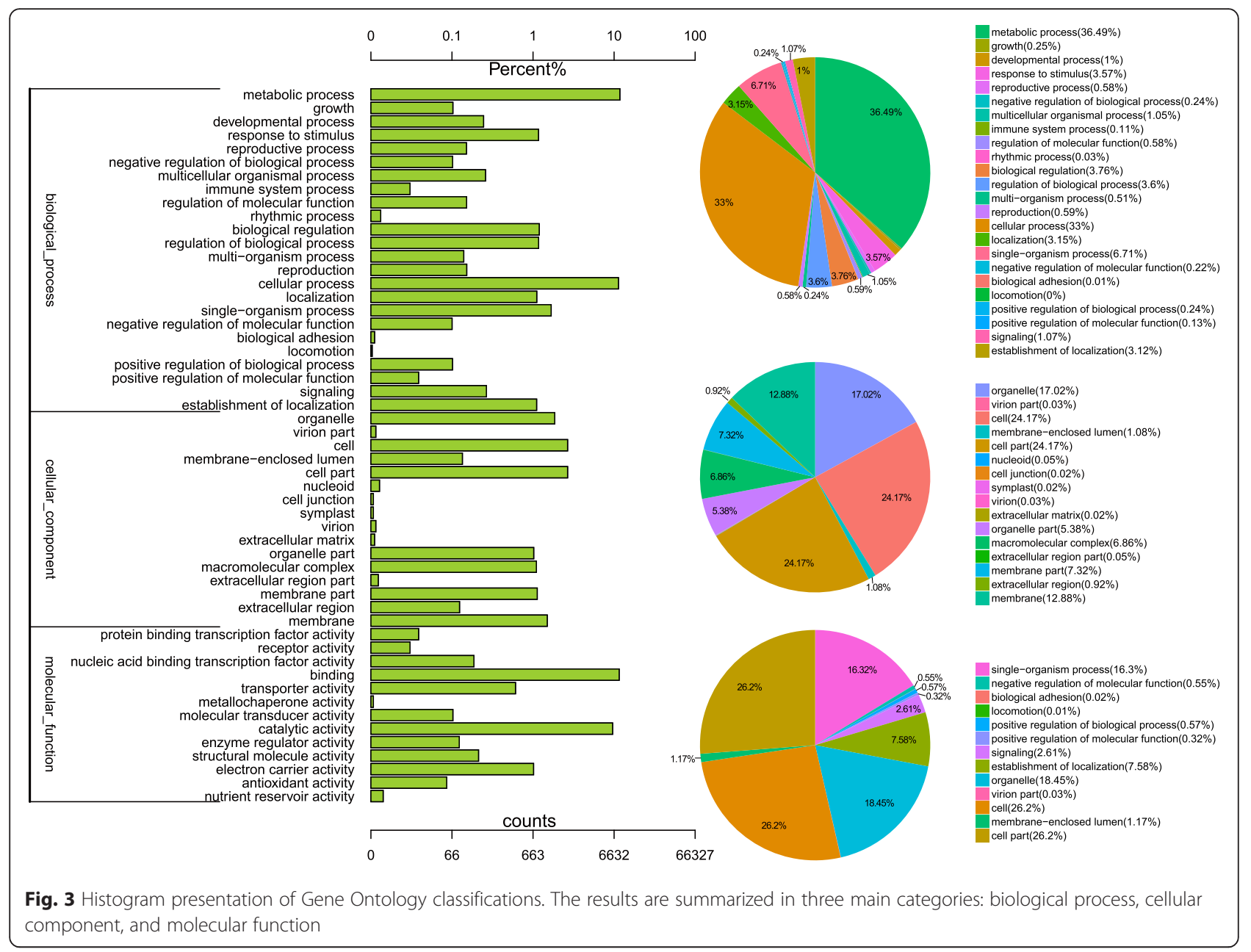

vernalization-related genes (LoVRN2) decreased sharply in vernalized sample than in unvernalized sample, which indicated that LoVRN2 may play an important role in floral induction. The expression of LoFLC was higher in 42vernalized stage when the LOSOC1 gene highly expressed than in 35-vernalized stage, which indicated that LoFLC may delay the floral transition. Growth hormone-related genes (LoAP2, LoIAA1, LoARF10) were higher in unvernalized sample than in vernalized and flower differentiation samples and DNA methylation related genes (LoCMT, $L o F L D)$ expressed differently in all stages. We predicted that the bulb has played an important role in for the Oriental hybrid lily adaptation to low temperature and completing vernalization.

Another new figure (Fig. 7) of the expression profiles of 12 transcripts in Oriental hybrid lily by RNA-seq was made in order to correspond to the expression of the same genes by qRT-PCR in Fig. 1 . The symbol'V-42' in Fig. 1 is on behalf of the samples that were obtained after 42-days vernalization, which happens to be the timing of bulbs'dormancy-breaking stage in Fig. 7 It is found that the expression of LoSVP, LoFLC, LoVRN2 genes by qRT-PCR are not agreed with those from RNAseq. The expression of LoSVP gene in Fig. 7 was highest in the dormant stage, however the gene expressed highest in the V-42 period in Fig. 1. The expression of LoFLC gene increased in the differentiation stage in Fig. 7 but decreased in differentiation stage in Fig. 1. The LoVRN2 gene was in lower expression level in the dormancybreaking stage and differentiation stage in Fig. 1, but it kept expressing highly in Fig. 7.

\section{Phylogenetic analysis of DNA sequence and deduced amino acid sequence of LoSVP and LoVRN1}

In our EST database, the highest expressing transcript was homologous to shot vegetative phase gene (LoSVP) and vernalization 1 gene (LoVRN1). SVP encodes a nuclear protein that acts as a floral repressor and represses $F T$ expression via direct binding to the vCArG III motif in the $F T$ promoter. For further analysis, we thus screened the complete sequence of LoSVP and LoVRN1 from the Oriental hybrid lily cDNA library by 
Table 4 The KEGG biochemical pathways categorization of Oriental hybrid lily unigenes pathways

\begin{tabular}{|c|c|c|c|c|}
\hline KEGG Categories & Mapped-KO & Unigene-NUM & Ratio of No. & Pathway-ID \\
\hline DNA replication & 32 & 42 & 0.25 & ko03030 \\
\hline Oocyte meiosis & 32 & 93 & 0.56 & ko04114 \\
\hline $\mathrm{N}$-Glycan biosynthesisn & 32 & 54 & 0.33 & ko00510 \\
\hline Proteasome & 33 & 129 & 0.78 & ko03050 \\
\hline Glycerophospholipid metabolism & 34 & 73 & 0.44 & ko00564 \\
\hline Arginine and proline metabolism & 34 & 69 & 0.42 & ko00330 \\
\hline Nucleotide excision repair & 35 & 122 & 0.73 & ko03420 \\
\hline Starch and sucrose metabolism & 36 & 52 & 0.31 & ko00500 \\
\hline Peroxisome & 37 & 75 & 0.45 & ko04146 \\
\hline Amino sugar and nucleotide sugar metabolism & 37 & 74 & 0.45 & ko00520 \\
\hline Viral carcinogenesis & 39 & 81 & 0.49 & ko05203 \\
\hline Plant hormone signal transduction & 39 & 70 & 0.42 & ko04075 \\
\hline Endocytosis & 39 & 191 & 1.2 & ko04144 \\
\hline Meiosis-yeast & 41 & 89 & 0.54 & ko04113 \\
\hline Photosynthesis & 42 & 65 & 0.39 & ko00195 \\
\hline HTLV-I infection & 46 & 147 & 0.89 & ko05166 \\
\hline mRNA surveillance pathway & 47 & 140 & 0.84 & ko03015 \\
\hline RNA degradation & 49 & 139 & 0.84 & ko03018 \\
\hline Cell cycle-yeast & 53 & 103 & 0.62 & ko04111 \\
\hline Ribosome biogenesis in eukaryotes & 56 & 256 & 1.54 & ko03008 \\
\hline Cell cycle & 56 & 160 & 0.96 & ko04110 \\
\hline Epstein-Barr virus infection & 58 & 177 & 1.07 & ko05169 \\
\hline Ubiquitin mediated proteolysis & 60 & 149 & 0.90 & ko04120 \\
\hline Pyrimidine metabolism & 72 & 278 & 1.67 & ko00240 \\
\hline Protein processing in endoplasmic reticulum & 74 & 228 & 1.37 & ko04141 \\
\hline Oxidative phosphorylation & 81 & 192 & 1.16 & ko00190 \\
\hline Purine metabolism & 83 & 183 & 1.10 & ko00230 \\
\hline RNA transport & 89 & 184 & 1.11 & ko03013 \\
\hline Biosynthesis of amino acids & 96 & 250 & 1.51 & ko01230 \\
\hline Spliceosome & 99 & 230 & 1.39 & ko03040 \\
\hline Ribosome & 119 & 289 & 1.74 & ko03010 \\
\hline Microbial metabolism in diverse environments & 125 & 413 & 2.49 & ko01120 \\
\hline Biosynthesis of secondary metabolites & 333 & 965 & 5.81 & ko01110 \\
\hline Metabolic pathways & 781 & 1880 & 11.32 & ko01100 \\
\hline Others & 2243 & 8274 & 49.8 & \\
\hline
\end{tabular}

RACE. The putative transcription start and stop sites of LoSVP and LoVRN1 were amplified with gene-specific primers designed from the partial cDNA sequence.

The predicted molecular mass and $\mathrm{pI}$ value of LoSVP were $36.7 \mathrm{kDa}$ and 4.85 , respectively. The transcripts defined the LoSVP full-length cDNA sequence with putative open reading frames of 675 bp encoding predicted proteins of 224 amino acids (Fig. 8a). The DNA sequence and deduced amino acid sequence of Oriental hybrid lily $L O S V P$ showed similarities to members of SVP family from Arabidopsis, Elaeis and other plant species. Oriental hybrid lily LoSVP contains the highly conserved MADS-box from amino acids 3-57 and K-box from amino acids 86-176 conserved domains as detected by the Motif scan program implemented in the PROSITE database [37] and belonged to TypeII MADSbox protein. No signal peptide was predicted by SignalP (http://www.cbs.dtu.dk/services/SignalP-2.0/), which is 


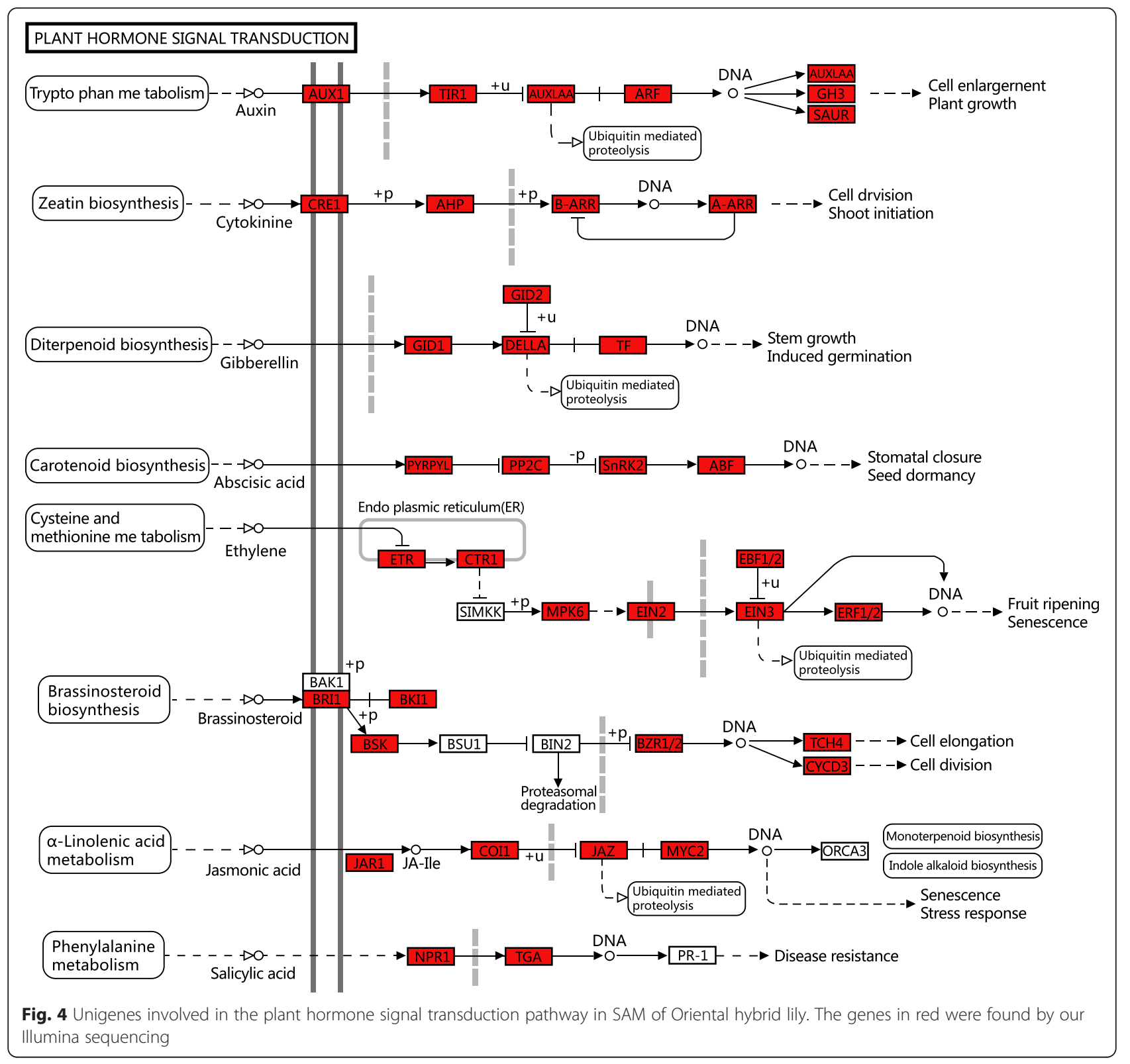

consistent with SVP found in other species. SVP was located in Nuclear by analyzing for subcellular localization (http://wolfpsort.seq.cbrc.jp/).

The predicted molecular mass and pI value of LoVRN1 were $32.5 \mathrm{kDa}$ and 6.54 , respectively. The transcripts defined the LoVRN1 full-length cDNA sequence with putative open reading frames of $561 \mathrm{bp}$ encoding predicted proteins of 186 amino acids (Fig. 8b). The DNA sequence and deduced amino acid sequence of Oriental hybrid lily LoVRN1 showed similarities to members of VRN1 family from Lilium longiflorum, Tulipa gesneriana and other plant species. Oriental hybrid lily LoVRN1 contains the highly conserved MADS-box from amino acids 3-57, K-box from amino acids 88-185 conserved domains and EF-hand calcium-binding domain from amino acids $60-72$ conserved domains as detected by the Motif scan program implemented in the PROSITE database [16] and belonged to TypeIIMADS-box protein. A signal peptide between 43 to 44 amino acids was predicted by SignalP, which is consistent with signal peptides found in VRN1s from other species. VRN1 was located in Nuclear by analyzing for subcellular localization.

An alignment of the deduced LoSVP and LoVRN1 with other plants SVPs and VRN1s showed that LoSVP and LoVRN1 shared high sequence identities with Elaeis guineensis LoSVP and Tulipa gesneriana LoVRN1, respectively (Fig. 9). Furthermore, an amino acid neighbor-joining tree was constructed for LoSVP 


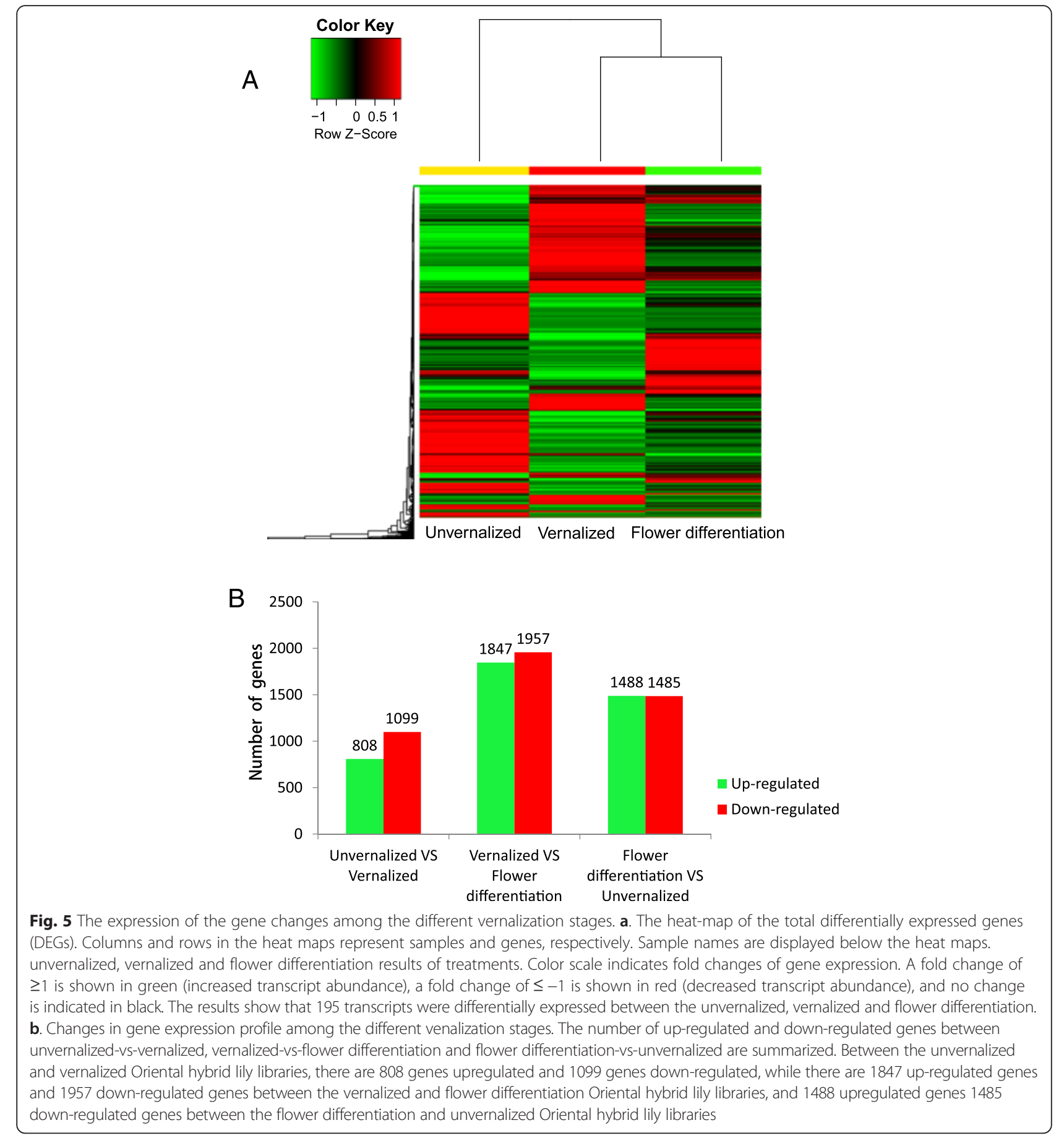

(Fig. 10a). Fifteen amino acid sequences of various plants were acquired from the Genbank database. A pairwise comparison of the degree of amino acid identity was performed for the SVPS. The identity shows high conservation of $S V P S$ in plants. In the $S V P$ amino acid tree, the $S V P$ of L. Oriental (LoSVP) is closely related to Elaeis guineensis, with high bootstrap value. The SVP of lily clustering with other monocots is a sister to a clade of other dicots. The phylogeny of SVP group indicateds that a single-class SVP gene existed before the divergence of dicots and monocots [16]. Twelve amino acid sequences of various plants were acquired from the Genbank database to construct an amino acid neighborjoining tree for LoVRN1 (Fig. 10b). A pairwise comparison of the degree of amino acid identity was performed for the VRN1s. The identity shows high conservation of $V R N 1 s$ in plants. In the VRN1 amino acid tree, the VRN1 of L. Oriental (LoVRN1) is closely related to 


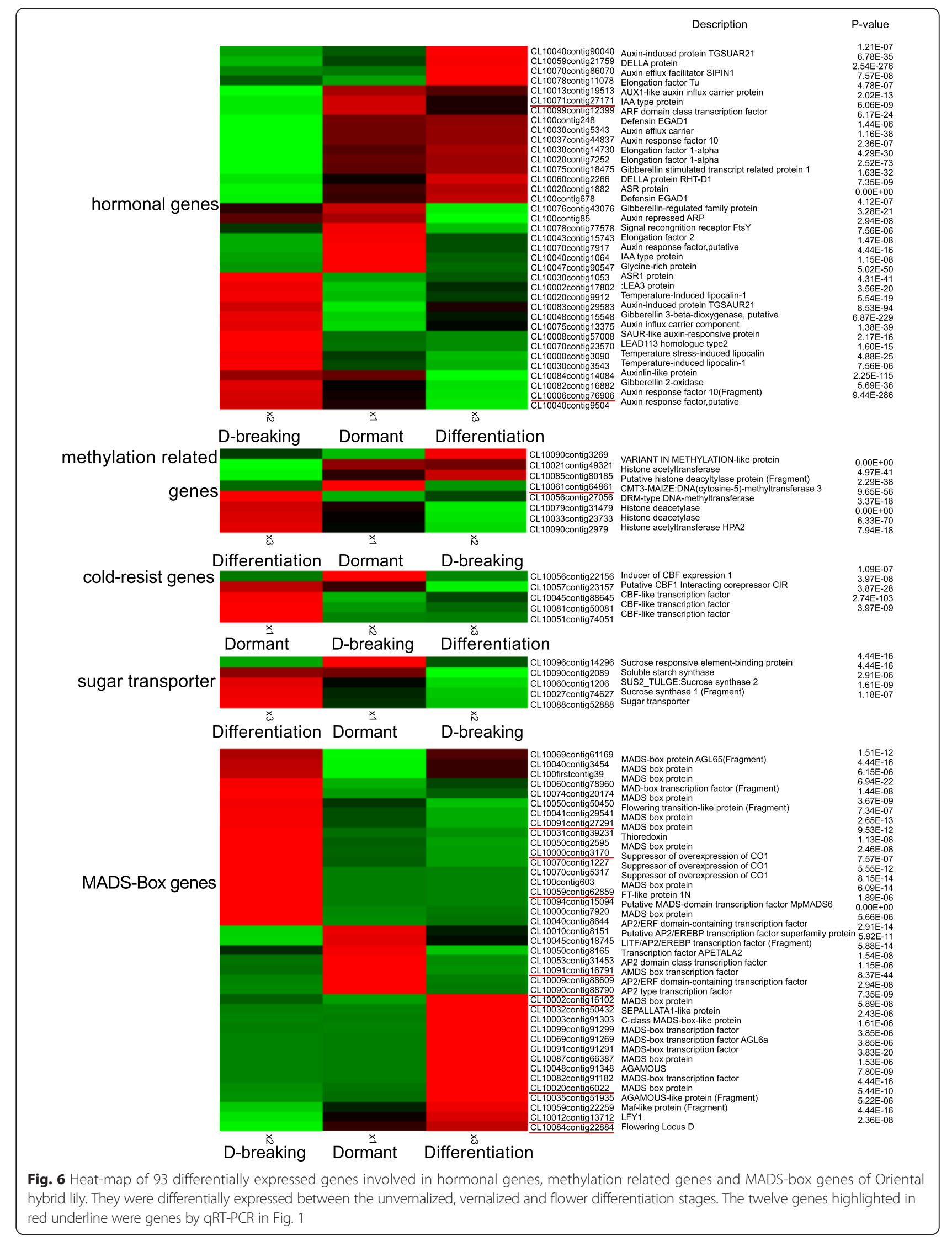




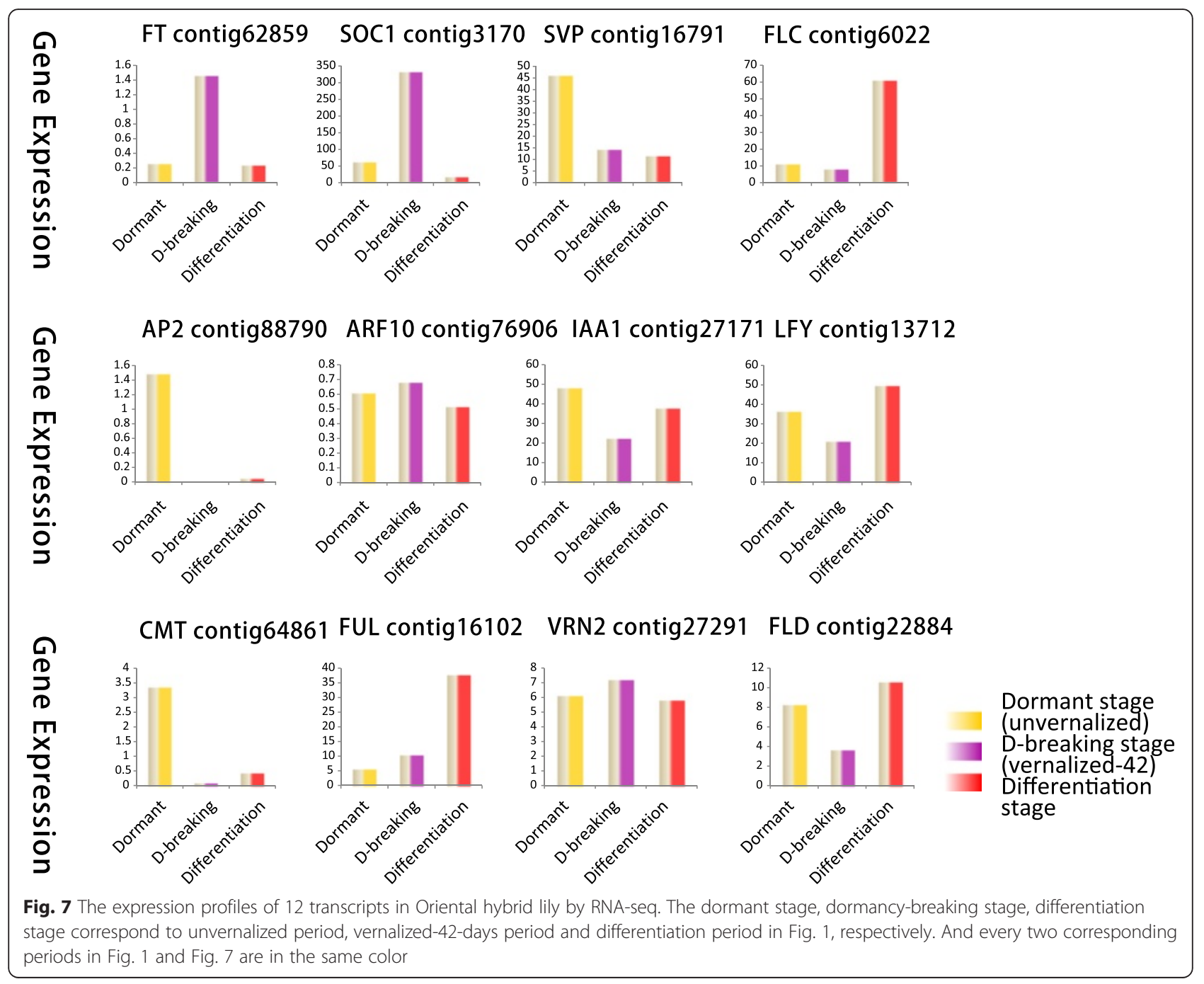

Lilium longiflorum, Tulipa gesneriana, with high bootstrap value.

\section{Ectopic expression of LoVRN1 causes early flowering and homeotic conversion of flowers in transgenic Arabidopsis plants}

To investigate the function of LoVRN1, the cDNAs of LoVRN1 gene driven by the cauliflower mosaic virus (CaMV) 35S promoter were transformed into Arabidopsis plants for functional analysis. Ten independent 35S:: LoVRN1 transgenic Arabidopsis T1 plants which flowered around 20d after germination were obtained, and showed identical phenotypes by flowering earlier than wild-type plants and great differences in the flower bud differentiation and flower organ development process. There mainly exhibited 5,6 or 7 valve performance traits in the late growth process of overexpressing LoVRN1 transgenic plants petals, while the wild-type plants were 4 petals (Fig. 11). In addition, by blade length and plant fresh weight statistical analysis, it showed some differences between overexpression LoVRN1 transgenic plants and wild-type plants (Fig. 11). The blade length of transgenic Arabidopsis plants was less than that of wild-type plants before the seed maturing stage. The plant fresh weight of transgenic Arabidopsis plants increases sharply than that of wild-type plants since the early blooming stage.

\section{Ectopic expression of LoSVP causes late flowering in transgenic Arabidopsis plants}

To investigate the function of LoSVP, the cDNAs of LoSVP gene driven by the cauliflower mosaic virus (CaMV) 35S promoter were transformed into Arabidopsis plants for functional analysis. Eight independent 35S:: LoSVP transgenic Arabidopsis T1 plants were obtained and showed identical phenotypes by flowering later than wild-type plants and some differences in blade length and plant fresh weight statistical analysis (Fig. 12). The blade length of transgenic Arabidopsis plants was always less than that of wild-type plants until the seed maturing stage. In Table. 5, the mean value of the leaf length of the LoSVP 


\section{a}

CACACTTGGTGCCTGATGGCGATTTTCTGATAGATGACCGGTAAGGCGCAATTTTACCATAAAAAGAGCCCCTCTACCCC CTTCCCGTACTGTAGTCTACACCTCCCATTCCCAATCTGAGATAGATCTCCGTCTACCACACCGGCAGGTTTACTCCATC TCCCGCGCTGCACTGGTGACTAGGGCTACGTCAGCACCTACCGGTAAGTGAGCTAATCATTATTAGGGTTGGTGGGTGGT GAGATCAG tg gcgagggagaagatacagataggaagatcgacaacgcggcggcceggcaggtgactttctcgaagcggeggeggggetg \begin{tabular}{l|llllllllllllllllllllllllllll}
$M$ & $A$ & $R$ & $E$ & $K$ & $I$ & $Q$ & $I$ & $R$ & $K$ & $I$ & $D$ & $N$ & $A$ & $A$ & $A$ & $R$ & $Q$ & $V$ & $T$ & $F$ & $S$ & $K$ & $R$ & $R$ & $R$ & $G$ & $L$
\end{tabular} ttcaagaggeggaggagttgtcagttctgtgcgacgccgacgttgctgtcatcatcttctcctcgaccggcaagctttccactttccacctcc

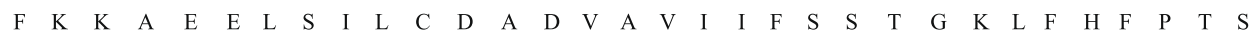
agtatacaggagatcattgacaagtacaatatgaactcgaagaacctacagaatgcagatcagccatctcttgaattgcagctagagagtagtgag

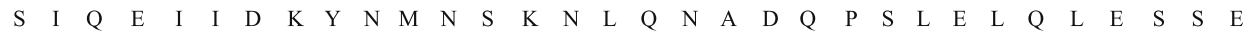
tacactagattgagggaacaagttgcagaagcaagccataacttagacgaatgagaggagaggagatccaagattaacattggatgagctgcaa

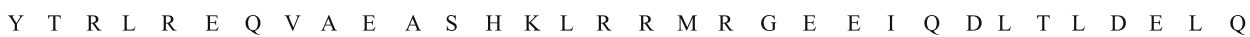
caattagagaaatccttgaaccggattaggcagggttatagaaggaagggtgctaaataatggaagaatcaatgttcttcgacagaagggt

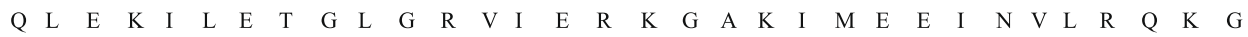
atgcagctgatggacgaaattctcgactgagacagcaagtggagattccagggaagggaagcaggtggtaactgttcagaacatatccgctac $\begin{array}{lllllllllllllllllllllllllllllllll}M & Q & L & M & D & E & N & S & R & L & R & Q & Q & V & E & I & S & R & E & G & K & Q & V & V & T & V & S & E & H & I & R & Y\end{array}$ gacgacggacagtcttctgaatcggtcacaa at attacacagatagaagagcagcaggactgtggtgaagctccgacacatcactcaaattaggg

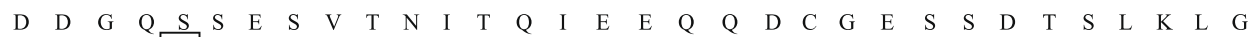
t a $\mathrm{g}$ c a a $\mathrm{a} g \mathrm{~g}$ a a a ATGTTGCTTGTGAGATTGTGATGATTCTTGAATTGAACAAGCTATGCCACTGGCCTATCACGGAATG \begin{tabular}{lllll}
$\mathrm{Y}$ & $\mathrm{A}$ & $\mathrm{Y}$ & $\mathrm{G}$ & $*$ \\
\hline
\end{tabular} ACACTTTTGTATAATTGTGTTACATGGAAGAGAAATTTCTCGGTGTTGATTGTATGGTAATTATAAATCTATCCCCCTAA CTGGTGTTAATAGGAGTCTTTGACAATTAATAATGCTGTCTTATTTAAAAAAA

\section{b}

CGCACTCCCTATATACCACCTGGTTTCCCAAAACCACCATCTATCCCATCTCTACTGCCCCCCTCATATC TCTAGCTCCCCTCTCATAATCATAAGTTCAAAGatggtcgagg aaggtc agctgag g gatcgagaa a g $\begin{array}{llllllllllllllllllll}\text { M } & G & R & G & K & V & Q & L & K & R & I & E & N & K\end{array}$ atcagccgccaagtcacctctccaa acgtcgaccggggctactgaagaaggcgcacgagatctccgtgctctgtgatgcggag $\begin{array}{llllllllllllllllllllllllllllllll} & \text { I } & \mathrm{S} & \mathrm{R} & \mathrm{Q} & \mathrm{V} & \mathrm{T} & \mathrm{F} & \mathrm{S} & \mathrm{K} & \mathrm{R} & \mathrm{R} & \mathrm{P} & \mathrm{G} & \mathrm{L} & \mathrm{L} & \mathrm{K} & \mathrm{K} & \mathrm{A} & \mathrm{H} & \mathrm{E} & \mathrm{I} & \mathrm{S} & \mathrm{V} & \mathrm{L} & \mathrm{C} & \mathrm{D} & \mathrm{A} & \mathrm{E}\end{array}$ atc gcactcatcgtcttctccaccaggggaagctgtacgagtactccaccgactccagcatggaaggattctcgaacgttac $\begin{array}{lllllllllllllllllllllllllllllllll}\text { V } & \text { A } & \text { L } & \text { I } & \text { V } & \text { F } & \text { S } & \text { T } & \text { R } & \text { G } & \text { K } & \text { L } & \text { Y } & \text { E } & \text { Y } & \text { S } & \text { T } & \text { D } & \text { S } & \text { S } & \text { M } & \text { E } & \text { R } & \text { I } & \text { L } & \text { E } & \text { R } & \text { Y }\end{array}$ gaacttattctcaagcagaa actgcagtgacagacacatatcctgaagcacagggaactggtgtcaagagtacggaagactg $\begin{array}{llllllllllllllllllllllllllllll}\text { E } & \text { L } & \text { Y } & \text { S } & \text { Q } & \text { A } & \text { E } & \text { T } & \text { A } & \text { V } & \text { T } & \text { D } & \text { T } & \text { Y } & \text { P } & \text { E } & \text { A } & \text { Q } & \text { G } & \text { N } & \text { W } & \text { C } & \text { Q } & \text { E } & \text { Y } & \text { G } & \text { R } & \text { L }\end{array}$ a a a c taaggttgaa accttgcagaa a gccaa agcaactcatgggggagcagctgaggacttgactctgaa a a actccaa $\begin{array}{lllllllllllllllllllllllllllll}\text { K } & \text { A } & \text { K } & \text { V } & \text { E } & \text { T } & \text { L } & \text { Q } & \text { K } & \text { S } & \text { Q } & \text { R } & \text { Q } & \text { L } & \text { M } & \text { G } & \text { E } & \text { Q } & \text { L } & \text { E } & \text { D } & \text { L } & \text { T } & \text { L } & \text { K } & \text { Q } & \text { L } & \text { Q }\end{array}$ caactagagcagcagctcgaattatcttcaagaatgtaagatcgaggaagcaccaactattgtttgattcgattaccgagctt $\begin{array}{lllllllllllllllllllllllllllll}\text { Q } & \text { L } & \text { E } & \text { Q } & \text { Q } & \text { L } & \text { E } & \text { L } & \text { S } & \text { F } & \text { K } & \text { N } & \text { V } & \text { R } & \text { S } & \text { R } & \text { K } & \text { H } & \text { Q } & \text { L } & \text { L } & \text { F } & \text { D } & \text { S } & \text { I } & \text { T } & \text { E } & \text { L }\end{array}$ cagcgaacagagaa tcactgcgggaacaaacactataatggagaaaagnnnnnnnnnnnnnagctcatggagttccaga $\begin{array}{llllllllllllllllllllllllllllll}Q & R & T & E & K & S & L & R & E & Q & N & T & I & M & E & K & K & X & X & X & X & X & S & S & W & S & S & R\end{array}$ a gatgggget tga CACAGCAAGATCACTGGGAGCTACAAGGACAACAGTACATGACAAGGCCCCCTCCTTT $\mathrm{R} \quad \mathrm{W} \quad \mathrm{G} \quad \mathrm{L}: *$

CCTGATGCCCCATTTGCACCCCGTCCAAAACAAAGGAGCCTACCCAGAAAGAGGCGGCAGCAGCAGCAGCG ACGCAGACGAGGGGGGAGCTGCACAGCAGCTGATTCGTGTTGGCAGCAGCTCACTACCGCCATGGATGCTT CGCCACGTTAACAGATGAGCTATCACCTTCCCCGCCTATCATAATTATTTTGCGGGGAATTCTGCTAAGTT TTACTATCAATCTTATAGCAGTAGAGGTCTGGTTTTGTTATGGTGTCACCCCTCTCGAAGAAAGGGGACAT AACTATACCGTATGTATAGGTTTATGCAATGGTATGCATAACTTTTGGTGAAGAGATCAATAAGCCTGTGA TGGTAGTGGTGTTTCTTTTGCTGCGTTCTGTATTTGGCTATCTATTGTACATGAAATAATATTTATGGAAA GCATCAGCTGTTTCTTTTGCTGTGTTGCTTGTCATATTTAGTTGACGCTGTATTTTGTAGCCAAGGAGCAA CCGTTGTAGGCTCTGATAAAGGGAGAGTTGCCCCTATCAGGTGTCATGTTTTGAATTTATCACATAAATCG $\mathrm{C}$

Fig. 8 Analysis of cDNA sequence encoding a SVP protein $\mathbf{a}$ and a VRN1 protein $\mathbf{b}$ isolated from Oriental hybrid lily. Nucleotide and deduced amino acid sequences of the SVP and VRN1 protein 


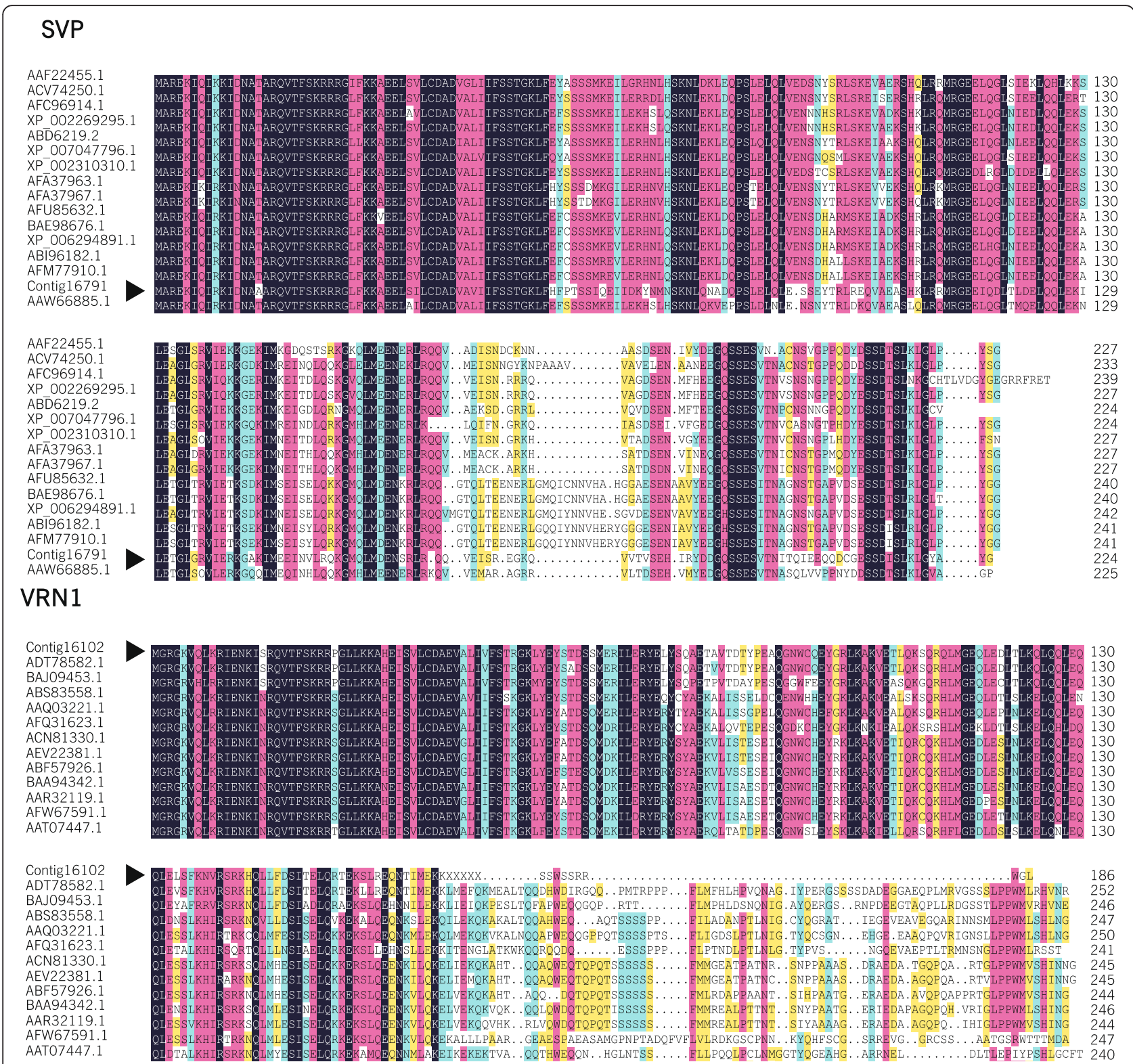

Fig. 9 Protein sgquence multiple alignment of the deduced amino acid sequences of LOSVP and LoVRN1 with other plant SVPS and VRN1s. The GenBank accession numbers of SVP are as follows: Theobroma cacao (XP 007047796), Populus trichocarpa (XP 002310310), Paulownia kawakamii (AAF22455.1), Vitis vinifera (XP 002269295), Vitis vinifera (AFC96914.1), Malus domestica (ABD66219.1), Brassica rapa (ABI96182.1), Brassica napus (AFM77910.1), Capsella rubella (XP 006294891), Arabidopsis thaliana (AFU85632.1), Arabidopsis thaliana (BAE98676.1), Petunia $\times$ hybrida (ACV74250.1), Actinidia chinensis (AFA37963.1), Actinidia chinensis (AFA37967.1), Elaeis guineensis (AAW66885.1). The GenBank accession numbers of VRN1 are as follows: Festuca arundinacea (ACN81330.1), Lolium perenne (AEV22381.1), Triticum aestivum (ABF57926.1), Dendrocalamus latiflorus (AAR32119.1), Oryza saliva (Baa94342.1), Zea mays (AFW67591.1), Elaeis guineensis (AAQ03221.1), Alpinia oblongifolia (ABS83558.1), Cymbidium ensifolium (AFQ31623.1), Vitis vinifera (AAT07447.1), Tulipa gesneriana (BAJ09453.1), Lilium longiflorum (ADT78582.1). LOSVP and LoVRN1 are indicated with an arrow at the left

transgenetic plants is $1.58 \mathrm{~cm}$, which is less than that of wild-type plants of $1.67 \mathrm{~cm}$ in the seedling stage. The mean value of the fresh weight of the LoSVP transgenetic plants is $0.34 \mathrm{~g}$, which is also less than that of wild-type plants of $0.39 \mathrm{~g}$ in the seedling stage. In the same way, we can notice that the blade length and fresh weight data of transgenic Arabidopsis plants were more than those of wild-plants both in the early blooming stage and seed maturing stage, which were marked in red in Table 5 . Similarly, the same conclusion can be obtained in Fig. 12.

\section{Discussion}

Plant hormone signal transduction in vernalization

Plant hormones could affect diverse developmental processes and were small organic molecules [38]. In our study, we found that plant hormones were involved in 

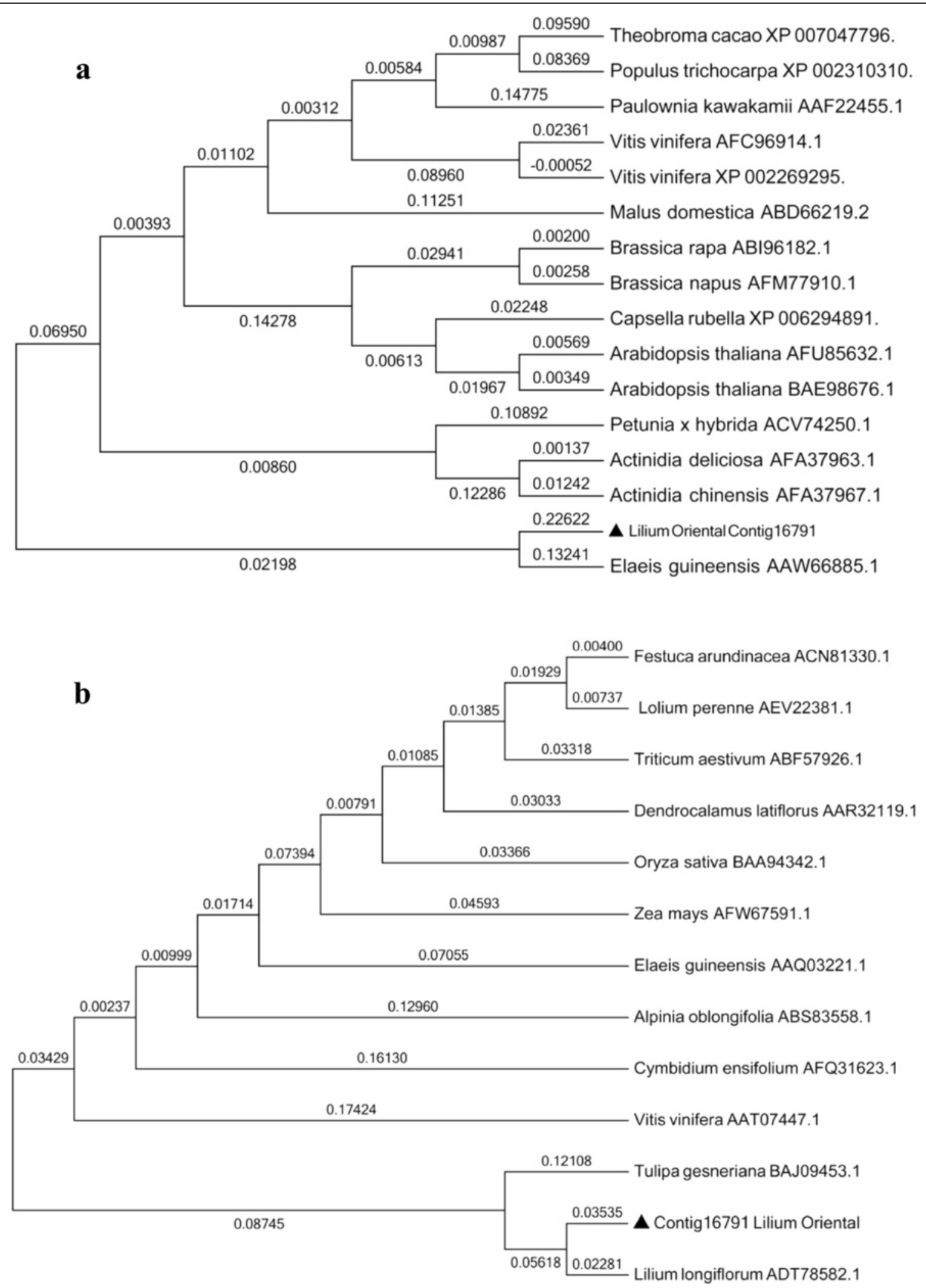

Fig. 10 Phylogenetic tree of L. Oriental LOSVP with 15 other plant SVPS and LoVRN1 with 12 other plant VRN1s based on deduced amino acid sequences 


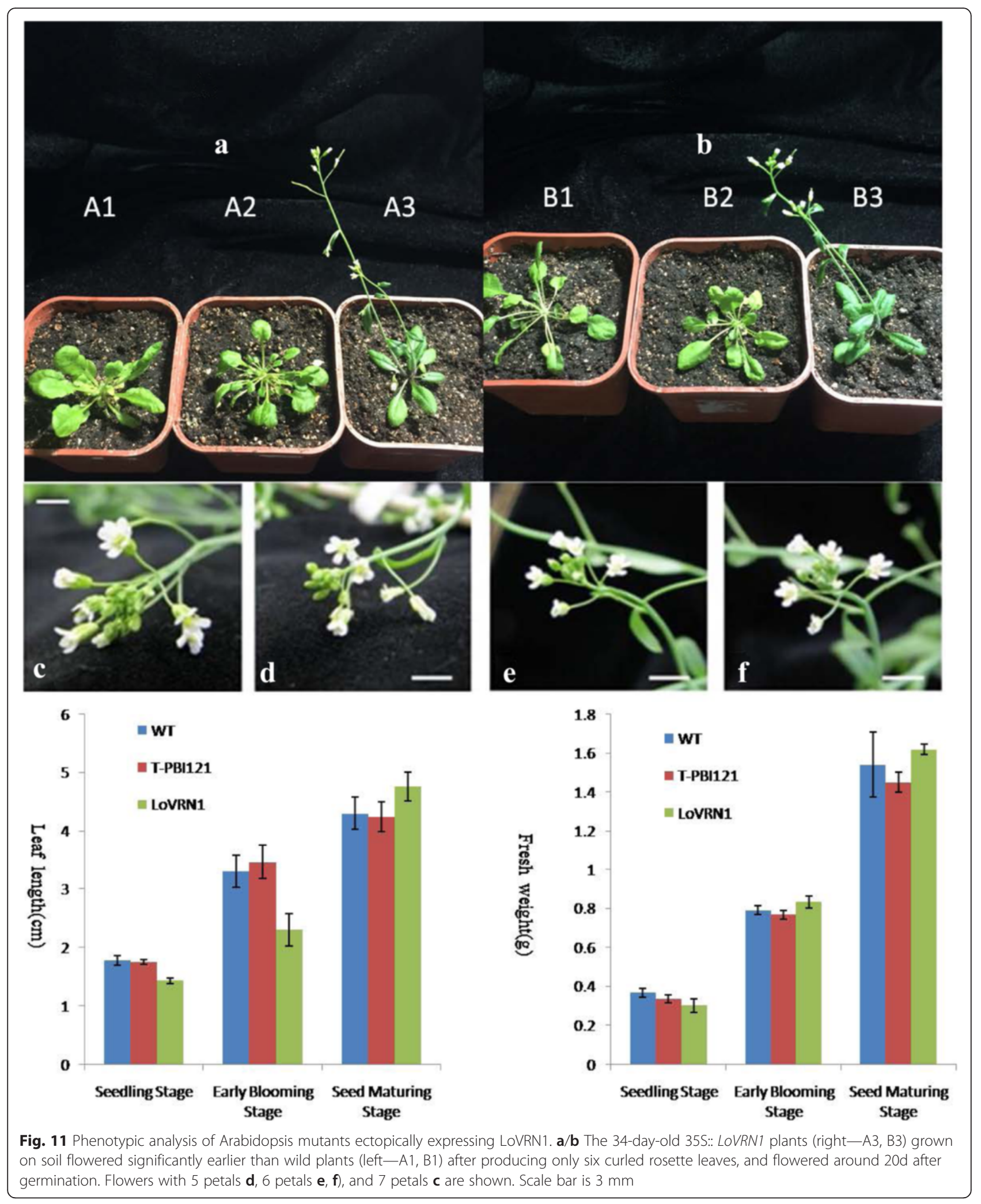




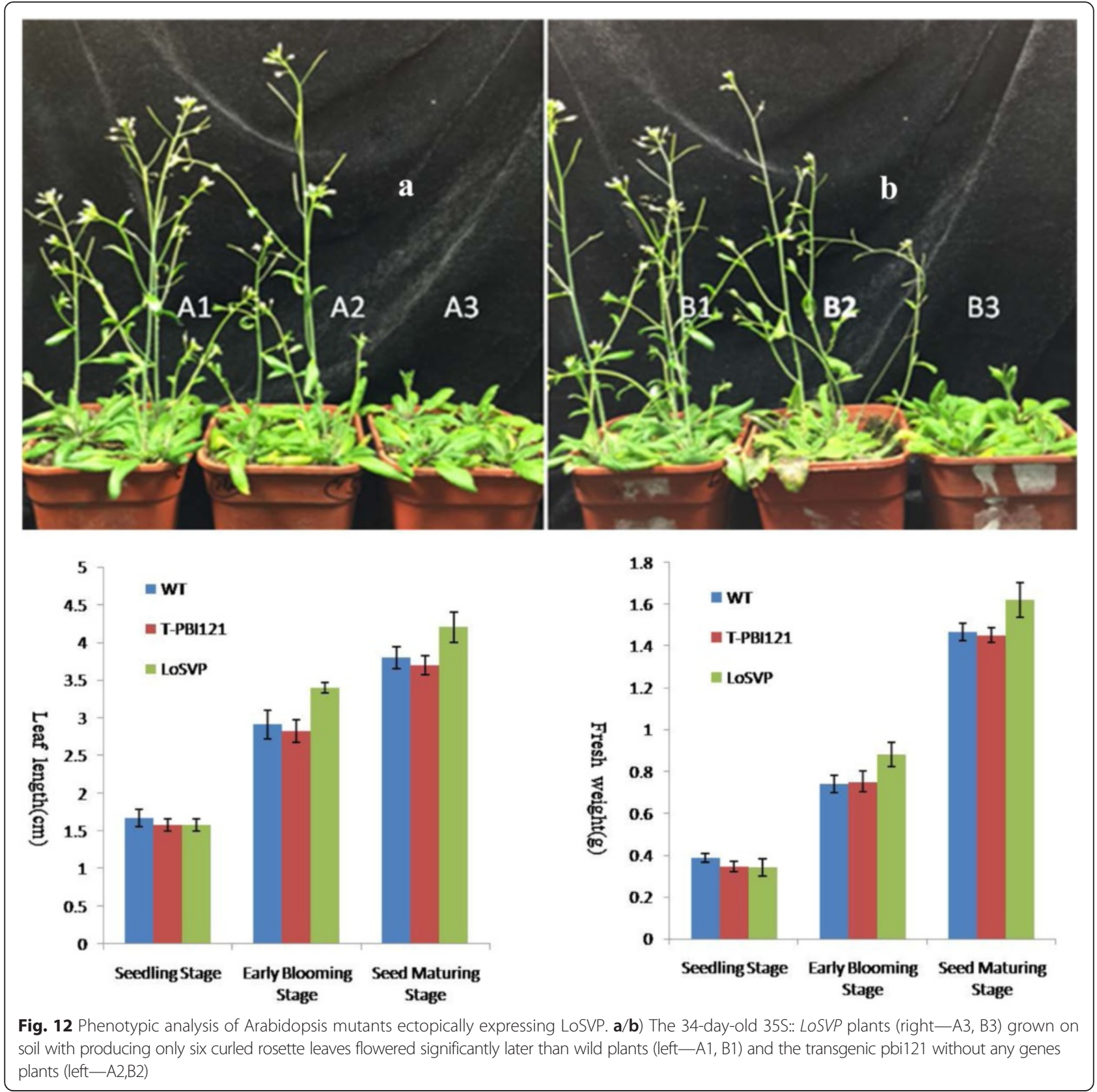

the flower differentiation of lily as ARF10, IAA1 genes and ethylene gene AP2 expressed differently (Fig. 1) among the three samples, especially at the dormancybreaking bulbs stored at $4{ }^{\circ} \mathrm{C}$ indicates that auxin is produced in the shoot during the cold treatment period, which leads to shoot emergence, floral stalk elongation and finally the flowering. These data will be valuable resources for investigations towards understanding specific auxin responses or a subset of auxin responses as well as hormonal crosstalk during the floral induction phase in vernalization. Previous study showed that IAA was present in the shoot apexes throughout the floral induction process, gradually concentrating in the shoot apical meristem (SAM). That study also suggested that IAA was the significant agent for floral induction, and that SAM might be the place of the main action [39]. Finally, an appropriate amount of IAA in the SAM and normal polar auxin transport are essential for floral induction and differentiation in Lily. In our study, we found growth hormone-related genes (LoAP2, LoIAA1, LoARF10) were higher in unvernalized sample than in vernalized and flower differentiation samples. Another study also showed that both IAA and ethylene application inhibit flower induction in the short-day plant 
Table 5 Effect of different transgenic treatment on morphological changes during Arabidopsis plants development

\begin{tabular}{|c|c|c|c|c|}
\hline Morphological traits & Treatment & Seedling Stage & Early Blooming Stage & Seed Maturing Stage \\
\hline \multirow[t]{3}{*}{ Leaf length $(\mathrm{cm})$} & WT & $1.78 \pm 0.08^{b}$ & $3.3 \pm 0.27^{d}$ & $4.30 \pm 0.27^{e}$ \\
\hline & T-PB|121 & $1.75 \pm 0.04^{b}$ & $3.46 \pm 0.29^{d}$ & $4.24 \pm 0.25^{e}$ \\
\hline & LoVRN1 & $1.43 \pm 0.04^{a}$ & $2.30 \pm 0.27^{c}$ & $4.76 \pm 0.25^{f}$ \\
\hline \multirow[t]{3}{*}{ Fresh weight (g) } & WT & $0.37 \pm 0.02^{\mathrm{a}}$ & $0.79 \pm 0.02^{b}$ & $1.54 \pm 0.17^{\mathrm{e}}$ \\
\hline & T-PB|121 & $0.34 \pm 0.02^{\mathrm{a}}$ & $0.77 \pm 0.02^{b}$ & $1.45 \pm 0.05^{c}$ \\
\hline & LoVRN1 & $0.30 \pm 0.04^{a}$ & $0.83 \pm 0.03^{b}$ & $1.62 \pm 0.03^{e}$ \\
\hline \multirow[t]{3}{*}{ Leaf length (cm) } & WT & $1.67 \pm 0.12^{\mathrm{a}}$ & $2.91 \pm 0.19^{b}$ & $3.80 \pm 0.14^{d}$ \\
\hline & T-PB|121 & $1.58 \pm 0.08^{\mathrm{a}}$ & $2.82 \pm 0.15^{b}$ & $3.70 \pm 0.12^{d}$ \\
\hline & LoSVP & $1.58 \pm 0.08^{\mathrm{a}}$ & $3.40 \pm 0.07^{c}$ & $4.20 \pm 0.2^{e}$ \\
\hline \multirow[t]{3}{*}{ Fresh weight (g) } & WT & $0.39 \pm 0.02^{a}$ & $0.74 \pm 0.04^{b}$ & $1.47 \pm 0.04^{d}$ \\
\hline & T-PB|121 & $0.34 \pm 0.03^{\mathrm{a}}$ & $0.75 \pm 0.05^{b}$ & $1.45 \pm 0.04^{d}$ \\
\hline & LOSVP & $0.34 \pm 0.04^{a}$ & $0.88 \pm 0.06^{c}$ & $1.62 \pm 0.08^{\mathrm{e}}$ \\
\hline
\end{tabular}

Note: ${ }^{\mathrm{Y}}$ Date are means of eight independent biological replicates $( \pm \mathrm{SEM}) ;{ }^{\mathrm{X}}$ Mean separation within columns by Duncan's multiple range test at $P \leq 0.05$ (lowercase letter)

Pharbitis nil and the inhibitory effect of IAA on flowering is not physiological but is connected with its effect on ethylene biosynthesis [40]. Other hormones, such as GAs and cytokinins might also be involved in flower development through changes in concentration or by interaction with other hormones during the period of storage at cold or during growth of shoots of bulbs in greenhouses [39]. Therefore, it may have important significance to find more genes in the GA floral induction pathway in later researches of Lily.

\section{Basal metabolism and DNA methylation play important roles in lily vernalization process}

In early twentieth century, scientists proved that the nutritional status of plants could influence plant flowering through a lot of experiments. The results of the study showed that the gene expression in starch, carbohydrate metabolism and nitrogen metabolism, were significantly up- regulated during vernalization. FLD encoding a plant ortholog of the human protein LysSpecific Demethylase1 (LSD1), is involved in H3K4 demethylation, [39], involed in positive regulation of flower development, inflorescence development, auxin biosynthetic process, cotyledon development, histone deacetylation, and oxidation-reduction process.. Lesions in FLD result in hyperacetylation of histones in $F L C$ chromatin, up-regulation of $F L C$ expression and extremely delayed flowering [40]. Although cross talk between demethylation and histone deacetylation has previously been indicated to modulate gene expression in mammalian cells, the direct association of FLD and CMT with a histone demethylase has not been reported. In our study, we found that the expression of DNA methylation genes LoCMT and LoFLD, which expressed differently among the three stages. These results suggest that CMT and $F L D$ play an important role in the interplay between histone deacetylation and DNA methylation in transcriptional regulation. This is a solid foundation for further characterization of the LoCMT and LoFLD. The expression of vernalization-related genes (LoVRN2) decreased sharply in vernalized sample than in unvernalized sample, which indicated that LoVRN2 may play an important role in floral induction. While previous studies in wheat and barley have revealed the functional role of histone modification in setting VRN1 expression [43]. Here, we are interested in determining whether the cold-induced expression of the LoVRN2 gene is associated with a change in DNA methylation, which will be my next research. Our study provides evidence of the role of DNA methylation in vernalization for Lily, which is necessary for the transition to reproductive growth.

\section{Genetic potential of LoVRN1 and LoSVP applied in lily}

LoVRN1 and LoSVP had important roles in the growth and development of plants, both could promote plant growth and transition from vegetative to reproductive growth, namely impacting flower transition [41, 42, 44]. Combined with previous transcriptome analysis, we speculated that LoVRN1 and LoSVP played important roles in lily flowering regulation. To further explore the molecular mechanism of lily vernalization process and understand the relationship between vernalization and LoVRN1 and LoSVP, and the relationship between LoVRN1 and LoSVP and flowering time, we cloned LoVRN1 and LoSVP genes. Through bioinformatics analysis and transgenic analysis, we found LoVRN1 could response to lily vernalization process and promote early flowering. In addition, there was a certain role of 
LoVRN1 gene in changing the type of lily. On the other side, LoSVP had a role in delaying flowering time. Due to the current genetic transformation based on genetic engineering and genetic modification techniques applied in a wide range of production and some crops, it was possible to overexpress LoVRN1 and LoSVP in lily to change the flowering time of lily. Previous studies showed that the up-regulation of VRN1 during winter is required to maintain low transcript levels of $V R N 2$, accelerate the induction of $F T$ in the leaves, and regulate a timely flowering in the spring. What just conforms this hypothesis in our study is that the expression of vernalization-related genes (LoVRN2) decreased sharply in vernalized sample than in unvernalized sample. But this hypothesis was reinforced by the observation that vernalization promotes an active chromatin state in $V R N 1$ regulatory regions but not in those of VRN2 or FT [45]. Another study also demonstrates that the down-regulation of VRN2 during vernalization does not require the presence of VRN1 [46]. Therefore, it will be an important research direction of how genes interact on each other during vernalizaiton. The understanding of functions of genes and the regulatory mechanisms involved in the initiation of flowering, especially the vernalization promotion pathway, will be beneficial to promote flowering of lily.

\section{Conclusion}

In conclusion, this study provides the first set of comprehensive floral transcriptome data in Oriental hybrid lily 'Sorbonne'. 66,327 Orential hybrid lily unigenes that provide information on gene expression patterns involved in the plant's vernalization and flower development were generated. From a functional categorization analysis of unigenes, followed by realtime qRT-PCR analysis, we found a high expression of genes involved in the low temperature response and flower development, especially we found that plant hormones signal transduction, DNA methylation were involved in the process of lily responses to vernalization under low temperature. The cDNAs identified from the cDNA library include two vernalizaitonrelated genes (LoSVP and LoVRN1), which appear to be promising candidates for playing key roles in the development and response of flowering in Oriental lily plants. One of the new practice of this manuscript was to collect a sample for transcriptome sequencing and comparison when the bulb's apical meristem was in the time of floral transition in which the expression of floral transition key gene SOC1 increased sharply by the qRT-PCR (Fig. 1) and the apical meristem had not converted into the morphological differentiation process, which helped to obtain more genes playing key roles in the floral induction pathways, such as vernalization pathway, gibberellic acid pathway, autonomous pathway and so on. Another new practice of this manuscript was to detect the relative expression of 12 genes, all of which are known to be related to low temperature, by qRT-PCR using samples which be collected every other week in vernalization stage besides other two samples in unvernalized stage and flower bud differentiation stage. The upstream and downstream relationship between different genes were forecasted by the analysis of genes' expression levels in a wide range of time (Fig. 4, Fig. 1). The above two points both promoted establishing and perfecting the molecular mechanisms of floral induction pathway by vernalization.

\section{Acknowledgments}

This work was supported by the China National Natural Science Foundation (Grant No. 31071815 and No. 31272204), '863' research program (Grant No. 2011AA10020804), and the D. Programs Foundation of the Ministry of Education of China (Grant No. 20110014110006).

\section{Authors' contributions}

WL carried out studies of total RNA isolation, transcriptome library construction, qRT-PCR of 12 genes which play important roles in flowering, isolation of LOSVP and LoVRN1, analysis of the phylogenetic relationship of LOSVP and LoVRN1, Arabidopsis transformation and transgenic plants analysis and drafted the manuscript and revised it critically for important intellectual content. XL have made substantial contributions to conception and design, carried out the study of identification and bioinformatics annotation of different genes, and participated in drafting the manuscript. $W L$ and $X L$ carried out transcriptome sequencing and interpreted data together. WL and $\mathrm{XL}$ contributed equally to this study and should be regarded as co-first authors. Corresponding author YL conceived of the study, participated in its design and coordination and have given final approval of the version to be published. All authors read and approved the final manuscript.

\section{Competing interests}

The authors declare that they have no competing interests.

Received: 5 August 2015 Accepted: 20 July 2016

Published online: 22 August 2016

\section{References}

1. Kim DH, Doyle MR, Sung S, Amasino RM. Vernalization: winter and the timing of flowering in plants. Annu Rev Cell Dev Biol. 2009;25:277-99.

2. Michaels SD, Amasino RM. FLOWERING LOCUS Cencodes a novel MADS domain protein that acts as a repressor of flowering. Plant Cell. 1999;11: 949-56.

3. Sheldon CC, Burn JE, Perez PP, Metzger J, Edwards JA, Peacock WJ, Dennis ES. The FLFMADS box gene: a repressor of flowering in Arabidopsis regulated by vernalization and methylation. Plant Cell. 1999;1 1:445-58

4. Schonrock N, Bouveret R, Leroy O, Borghi L, Kohler C, Gruissem W, Hennig L. Polycomb-group proteins repress the floral activator AGL19 in the FLCindependent vernalization pathway. Genes Dev. 2006;20:1667-78.

5. Seo E, Lee H, Jeon J, Park H, Kim J, Noh YS, Lee I. Crosstalk between cold response and flowering in Arabidopsis is mediated through the flowering-time gene SOC1 and its upstream negative regulator FLC. Plant Cell. 2009;21:3185-97.

6. Yoo SK, Chung KS, Kim J, Lee JH, Hong SM, Yoo SY, Lee JS, Ahn JH. CONSTANS activateS SUPPRESSOR OF OVEREXPRESSION OF CONSTANS 1 through FLOWERING LOCUS T to promote flowering in Arabidopsis. Plant Physiol. 2005;139:770-8.

7. Searle I, He Y, Turck F, Vincent C, Fornara F, Krober S, Amasino RA, Coupland $G$. The transcription factor FLC confers a flowering response to vernalization by repressing meristem competence and systemic signaling in Arabidopsis. Genes Dev. 2006;20:898-912.

8. Aikawa S, Kobayashi MJ, Satake A, Shimizu KK, Kudoh H. Robust control of the seasonal expression of the Arabidopsis FLC gene in a fluctuating environment. Proc Natl Acad Sci U S A. 2010;107:11632-7.

9. Pin PA, Benlloch R, Bonnet D, Wremerth-Weich E, Kraft T, Gielen JJ, Nilsson O. An antagonistic pair of FT homologs mediates the control of flowering time in sugar beet. Science. 2010;330:1397-400. 
10. Cheng C, Yun K-Y, Ressom HW, Mohanty B, Bajic VB, Jia Y, Yun SJ, Reyes $B G D$. An early response regulatory cluster induced by low temperature and hydrogen peroxide in seedlings of chilling-tolerant japonica rice. BMC Genomics. 2007:8(7):175.

11. Trevaskis $B$. The central role of the VERNALIZATION1 gene in the vernalization response of cereals. Funct Plant Biol. 2010;37:479-87.

12. Raherison E, Rigault P, Caron S, Poulin P, Boyle B, Verta JP, Giguere I, Bomal C, Bohlmann J, MacKay J. Transcriptome profiling in conifers and the PiceaGenExpress database show patterns of diversification within gene families and interspecific conservation in vascular gene expression. BMC Genomics. 2012;13:434-49.

13. Yan L, Loukoianov A, Tranquilli G, Helguera M, Fahima T, Dubcovsky J. Positional cloning of the wheat vernalization gene VRN1. Proc nat Acad Sci. 2003;100:6263-8.

14. Yan L, Loukoianov A, Blechl A, Tranquilli G, Ramakrishna W, Sanmiguel P, Bennetzen J, Echenique V, Dubcovsky J. The wheat VRN2 gene is a flowering repressor down-regulated by vernalization. Science. 2004;303:1640-4.

15. Liu C, Zhou J, Bracha-Drori K, Yalovsky S, Ito T, Yu H. Specification of Arabidopsis floral meristem identity by repression of flowering time genes. Development. 2007;134:1901-10.

16. Trevaskis B, Tadege M, Hemming MN, Peacock WJ, Dennis ES, Sheldon C. Short vegetative phase-like MADS-box genes inhibit floral meristem identity in barley. Plant Physiol. 2007;143:225-35.

17. Kane NA, Agharbaoui Z, Diallo AO, Adam H, Tominaga Y, Ouellet F, Sarhan F. TaVRT2 represses transcription of the wheat vernalization gene TaVRN1. Plant J. 2007:51:670-80

18. Lee IL, Kyong CP, Ye SS, Jae HS, Soon JK, Jong KN, Jong HK, Nam SK. Development of expressed sequence tag derived-simple sequence repeats in the genus Lilium. Genes \& Genomics. 2011;33:727-33.

19. Mouradov A, Cremer F, Coupland G. Control of flowering time: interacting pathways as a basis for diversity. Plant Cell. 2002;14:111-30.

20. Xue J, Bao YY, Li B, Cheng YB, Peng ZY. Transcriptome analysis of the brown planthopper Nilaparvata lugens. PLoS ONE. 2010;5(12):e14233.

21. Cui J, Liu S, Zhang B, Wang H, Sun H, Song S, Qiu X, Liu Y, Wang X, Jiang Z, Liu Z. Transciptome Analysis of the Gill and Swimbladder of Takifugu rubripes by RNA-Seq. PLOS ONE. 2014:9(1):85505.

22. Zeng L, Choi SC, Danko CG, Siepel A, Stanhope MJ, Burne RA. Gene regulation by CcpA and catabolite repression explored by RNA-Seq in Streptococcus mutans. PLoS ONE. 2013;8(3):60465.

23. Crawford JE, Guelbeogo WM, Sanou A, Traoré A, Vernick KD, Sagnon NF, Lazzaro BP. De novo transcriptome sequencing in Anopheles funestus using Illumina RNA-seq technology. PLoS ONE. 2010;5(12):14202.

24. Liew LC, Singh MB, Bhalla PL. An RNA-Seq Transcriptome Analysis of Histone Modifiers and RNA Silencing Genes in Soybean during Floral Initiation Process. PLOS ONE. 2013;8(10):77502.

25. Zhou H, Cheng FY, Wang R, Zhong Y, He C. Transcriptome Comparison Reveals Key Candidate Genes Responsible for the Unusual Reblooming Trait in Tree Peonies. PLOS ONE. 2013:8(11):79996.

26. Gao QA, Jin $K$, Ying $S H$, Zhang $Y$ J, Xiao GH, Shang YF, Duan ZB, Hu XA, Xie XQ, Zhou G, Peng GX, Luo ZB, Huang W, Wang B, Fang WG, Wang SB, Zhong Y, Ma LJ, St Leger RJ, Zhao GP, Pei Y, Feng MG, Xia YX, Wang CS. Genome sequencing and comparative transcriptomics of the model entomopathogenic fungi Metarhizium anisopliaeandM. acridum. PLoS Genet. 2011;7:e1001264.

27. Conesa A, Gotz S, Garcia-Gomez JM, Terol J, Talon M, Robles M. Blast2GO: a universal tool for annotation, visualization and analysis in functional genomics research. Bioinformatics. 2005;21:3674-6.

28. Wang L, Feng Z, Wang X, Wang X, Zhang X. DEGseq: an R package for identifying differentially expressed genes from RNA-seq data. Bioinformatics. 2010;26:136-8.

29. Audic S, Claverie JM. The significance of digital gene expression profiles. Genome Res. 1997;7:986-95.

30. Livak KJ, Schmittgen TD. Analysis of relative gene expression data using real-time quantitative PCR and the $2^{-\Delta \Delta C t}$ method. Methods. 2001;25: 402-8.

31. Thompson JD, Higgins DG, Gibson TJ. CLUSTALW: improving the sensitivity of progressive multiple sequence alignment through sequence weighting, position-specific gap penalties and weight matrix choice. Nucleic Acids Res. 1994;22:4673-80.
32. Tamura K, Dudley J, Nei M, Kumar S. MEGA4: Molecular Evolutionary Genetics Analysis (MEGA) software version 4.0. Mol Biol Evol. 2007;24: 1596-9.

33. Felsenstein J. Confidence limits on phylogenies: an approach using the bootstrap. Evolution. 1985;39:783-91.

34. Hillis DM, Bull JJ. An empirical test of bootstrapping as a method assessing confidence in phylogenetic analysis. Syst Biol. 1993;42:41182-192.

35. Mattanovich D, Ruker F, Machado AC, Laimer M, Regner F, Steinkellner $H$, Himmber G, Katinger H. Efficient transformation of Agrobacterium spp. by electroporation. Nucleic Acid Res. 1989;17:7647.

36. Clough SJ, Bent AF. Floral dip: a simplified method for Agrobacteriummediated transformation of Arabidopsis thaliana. Plant J. 1998;16:735-43.

37. Falquet L, Pagni M, Bucher $P$, Hulo N, Sigrist CJA, Hofmann K, Bairoch A The PROSITE database, its status in 2002. Nucleic Acids Res. 2002;30:235-8.

38. Ashikari M, Sakakibara H, Lin S, Yamamoto T, Takashi T, Nishimura A Angeles ER, Qian Q, Kitano H, Matsuoka M. Cytokinin oxidase regulates rice grain production. Science. 2005;309:741-5.

39. Hou Z-X, Huang W-D. Immunohistochemical localization of IAA and ABP1 in strawberry shoot apexes during floral induction. Planta. 2005;222(4):678-87.

40. Kęsy J, Maciejewska B, Sowa M, Szumilak M, Kawałowski K, Borzuchowska M, Kopcewicz J. Ethylene and IAA interactions in the inhibition of photoperiodic flower induction of Pharbitis nil. Plant Growth Regul. 2008;551.

41. Jiang D, Yang W, He Y, Amasino RM. Arabidopsis relatives of the human lysine-specific Demethylase 1 repress the expression of FWA and FLOWERING LOCUS C and thus promote the floral transition. Plant Cell. 2007:19:2975-87.

42. Yu CW, Liu X, Luo M, Chen CY, Lin XD, Tian G, Lu Q, Cui YH, Wu KQ. HISTONE DEACETYLASE6 interacts with FLOWERING LOCUS D and regulates flowering in Arabidopsis. Plant Physiol. 2011;156(1):173-84.

43. Khan Abdul R, Enjalbert J, Marsollier A-C, Rousselet A, Goldringer I, Vitte C. Vernalization treatment induces site-specific DNA hypermethylation at the VERNALIZATION-A1 (VRN-A1) locus in hexaploid winter wheat. BMC Plant Biol. 2013:13:209.

44. Trevaaskis B, Bagnall DJ, Ellis MH, Peacock WJ, Dennis ES. MADS box genes control vernalization induced flowering in cereals [J]. Proc. Natl. Acad. Sci. PANS. 2003;100(22):13099-104.

45. Oliver SN, Finnegan EJ, Dennis ES, Peacock WJ, Trevaskis B. Vernalizationinduced flowering in cereals is associated with changes in histone methylation at the VERNALIZATION1 gene. Proc Natl Acad Sci U S A. 2009;106:8386-91.

46. Chen A, Dubcovsky J. Wheat TILLING Mutants Show That the Vernalization Gene VRN1 Down-Regulates the Flowering Repressor VRN2 in Leaves but Is Not Essential for Flowering. PLoS Genetics. 2012;812:e1003134.

\section{Submit your next manuscript to BioMed Central and we will help you at every step:}

- We accept pre-submission inquiries

- Our selector tool helps you to find the most relevant journal

- We provide round the clock customer support

- Convenient online submission

- Thorough peer review

- Inclusion in PubMed and all major indexing services

- Maximum visibility for your research

Submit your manuscript at www.biomedcentral.com/submit 